\title{
Glutaminolysis Mediated by MALT1 Protease Activity Facilitates PD-L1 Expression on ABC-DLBCL Cells and Contributes to Their Immune Evasion
}

OPEN ACCESS

Edited by:

Boris Zhivotovsky,

Karolinska Institutet (KI), Sweden

Reviewed by:

Catherine Brenner,

Institut National de la Santé et de la

Recherche Médicale (INSERM),

France

Denise P. Carvalho

Universidade Federal do Rio de

Janeiro, Brazil

*Correspondence:

Yunfei Gao

yunfei.gao@utoronto.ca

Specialty section:

This article was submitted to Molecular and Cellular Oncology,

a section of the journal

Frontiers in Oncology

Received: 27 September 2018 Accepted: 04 December 2018 Published: 18 December 2018

Citation:

Xia X, Zhou W, Guo C, Fu Z, Zhu L, Li P, Xu Y, Zheng L, Zhang H, Shan C

and Gao Y (2018) Glutaminolysis Mediated by MALT1 Protease Activity

Facilitates $P D-L 1$ Expression on $A B C$-DLBCL Cells and Contributes to

Their Immune Evasion.

Front. Oncol. 8:632.

doi: 10.3389/fonc.2018.00632

\section{Xichun Xia, Wei Zhou, Chengbin Guo, Zhen Fu, Leqing Zhu, Peng Li, Yan Xu, Liangyan Zheng, Hua Zhang, Changliang Shan and Yunfei Gao*} The First Affiliated Hospital, Biomedical Translational Research Institute and Guangdong Province Key Laboratory of
Molecular Immunology and Antibody Engineering, Jinan University, Guangzhou, China

Previous studies have demonstrated that programmed death-1 ligand 1 (PD-L1) expressed in an aggressive activated B-cell (ABC)/non-germinal center B cell-like (GCB) subtype of diffuse large B-cell lymphoma (DLBCL) is associated with inhibition of the tumor-associated T cell response. However, the molecular mechanism underlying PD-L1 expression in ABC-DLBCL remains unclear. Here, we report that MALT1 protease activity is required for $A B C$-DLBCL cells to evade cytotoxity of $\mathrm{V} \gamma 9 \mathrm{~V} \delta 2 \mathrm{~T}$ lymphocytes by generating substantial PD-L1+ ABC-DLBCL cells. While, NF-kB was dispensable for the PD-L1 expression induced by MALT1 protease activity in ABC-DLBCL cells. Furthermore, we showed that GLS1 expression was profoundly reduced by MALT1 protease activity inhibition, which resulted in insufficiency of glutaminolysis-derived mitochondrial bioenergetics. Activation of the PD-L1 transcription factor STAT3, which was strongly suppressed by glutaminolysis blockade, was rescued in a TCA (tricarboxylic acid) cycle-dependent manner by glutamate addition. Collectively, MALT1 protease activity coupled with glutaminolysis-derived mitochondrial bioenergetics plays an essential role in PD-L1 expression on ABC-DLBCL cells under immunosurveillance stress. Thus, our research sheds light on a mechanism underlying PD-L1 expression and highlights a potential therapeutic target to vanquish immune evasion by ABC-DLBCL cells.

Keywords: diffuse large B-cell lymphoma, MALT1 protease activity, glutaminolysis, PD-L1, immune evasion

\section{INTRODUCTION}

Diffuse large B-cell lymphoma (DLBCL) comprises the largest subgroup of non-Hodgkin lymphoma (NHL), accounting for $\sim 25 \%$ of all lymphoma cases (1). Gene expression profiling has allowed subclassification of DLBCL into at least two distinct molecular subtypes, including germinal center B cell-like (GCB) and activated B cell-like (ABC) DLBCL (2). The ABC subtype is aggressive, and patients with the $\mathrm{ABC}$ subtype have significantly shorter overall survival (OS) than those with the GCB subtype (3). Currently, R-CHOP (rituximab, cyclophosphamide, doxorubicin, vincristine, and prednisone) is the first-line treatment for DLBCL patients and has contributed to an overall improvement in patient survival (4). However, many patients with DLBCL are unresponsive to the treatment and generally have a poor prognosis, particularly patients with the $\mathrm{ABC}$ subtype $(5,6)$. This may be related to the antiapoptotic effects of NF- $\mathrm{kB}$ that counteract the action of

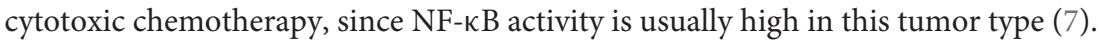




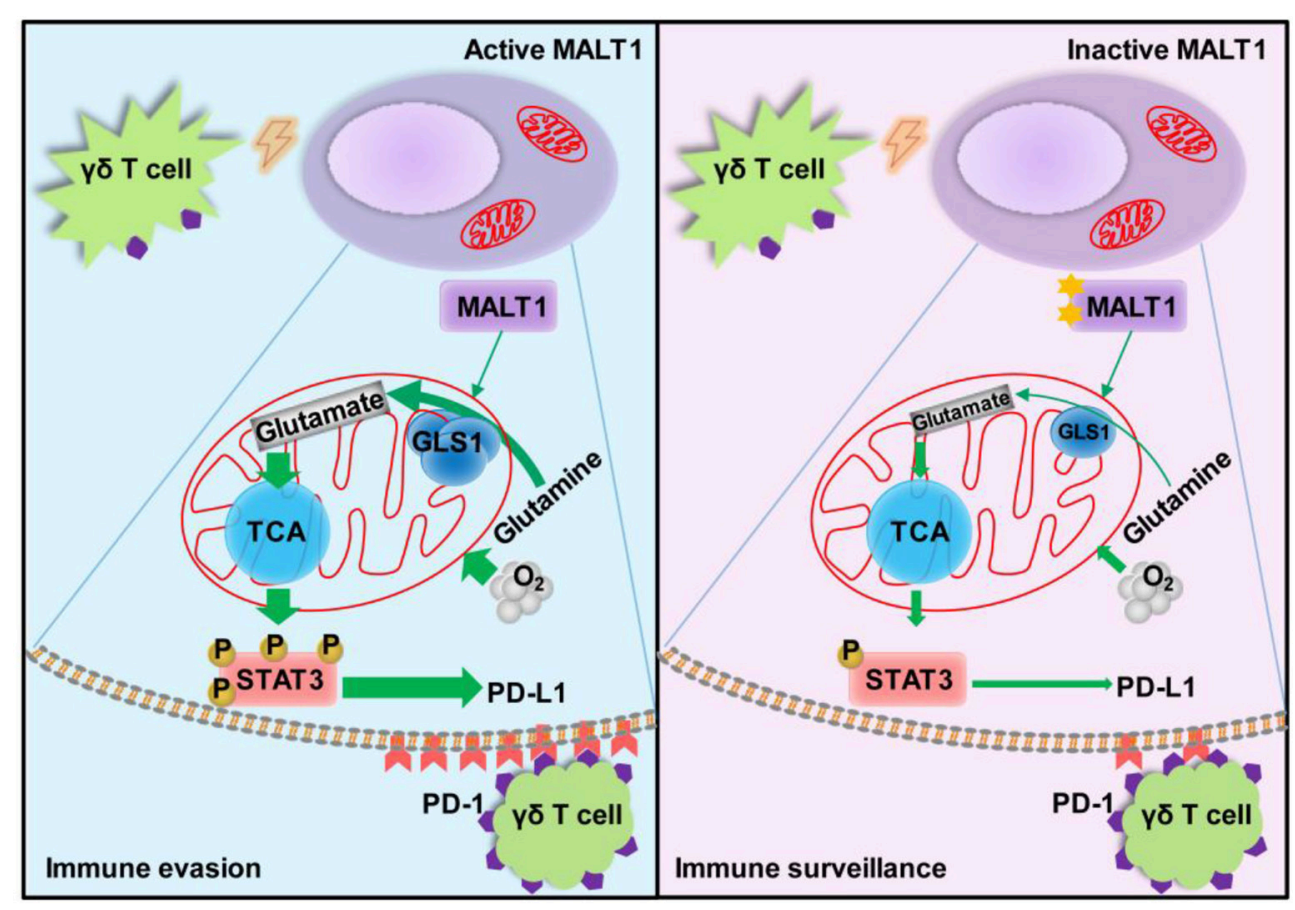

GRAPHICAL ABSTRACT | Under V $\gamma 9 \mathrm{~V} \delta 2 \mathrm{~T}$ lymphocytes stress, the glutaminolysis intermediate glutamate enhances mitochondrial bioenergetics, resulting in STAT3 activation and PD-L1 expression in ABC-DLBCL cells. This process is controlled by MALT1 protease activity via up-regulating GLS1 expression. These results show a novel regulatory pathway that endows ABC-DLBCL cells with an immunosuppressive property. Hence, manipulation of these pathways could hold enormous potential for the development of effective immunotherapy for ABC-DLBCL.

Tumor cells exploit the expression of programmed death-1 (PD-1) ligand 1 (PD-L1) to subvert T-cell-mediated immunesurveillance. In recent years, oncotherapy targeting the PD$1 / \mathrm{PD}$-L1 immune-checkpoint has shown promising results in the treatment of various carcinoma types, such as melanoma, renal cancer, and lung cancer (8). A study on B-cell NHL demonstrated that PD-L1 expression was confined to a subset of DLBCL with activated B-cell features, which carries a poorer prognosis and frequently recurs after conventional chemoimmunotherapy (9). PD-L1-positive DLBCL was significantly associated with nonGCB type and the OS of patients with PD-L1-positive DLBCL was inferior to that of patients with PD-L1-negative DLBCL (10). Blockade of PD-1 can restore the anti-tumor functions of T-cells in DLBCL-derived cell lines in vitro (11). Together, this evidence suggests that GCB-DLBCL and the aggressive ABC/non-GCB subtype of DLBCL use distinct molecular mechanisms to regulate PD-L1 expression, which is preferentially used by the latter to escape recognition and killing by $\mathrm{T}$ cells.

The success of therapies that disrupt PD-L1-mediated tumor tolerance highlights the need to understand the molecular regulation of PD-L1 expression (12). Recently, many studies have focused on the mechanism underlying PD-L1 expression. Georgiou et al. found that translocations between PD-L1 and the IGH locus led to PD-L1 overexpression in DLBCL, and this genetic alteration in the $P D-L 1$ locus is mainly associated with the non-GCB subtype of DLBCL (13). Further studies found that PD-L1 expression was regulated by kinase-cascade signaling pathways, transcription factors, and epigenetic factors. Both the $\mathrm{PI} 3 \mathrm{~K} / \mathrm{AKT}$ and MAPK pathways are involved in controlling PDL1 expression (14). Transcription factors, including regulatory elements responsive to IFN regulatory factor 1 (IRF1), NF- $\mathrm{B}$, hypoxia-inducible factor $1 \alpha(\mathrm{HIF} 1 \alpha)$, and STAT3, were found to bind to the PD-L1 gene promoter (15-17). Furthermore, recent reports provide a possible link between metabolic reprogramming and PD-L1 expression $(18,19)$. Oversupply of the glycolytic intermediate pyruvate to mitochondria enhances PD-L1 expression by fostering oxidative phosphorylation and TCA cycle activity in macrophages (19). However, our knowledge of PD-L1 expression regulation in DLBCL and the biological functions of the regulation is limited.

Mucosa-associated lymphoid tissue lymphoma translocation gene 1 (MALT1), originally identified in B-cell lymphoma, is a Cys-dependent, Arg-specific protease (20). After antigenic stimulation, MALT1 forms part of the CARMA1-BCL10MALT1 (CBM) complex and catalyzes protease activity that cleaves inhibitors of the NF- $\kappa \mathrm{B}$ signaling pathway, such as TNFAIP3/A20, BCL10 protein, CYLD, and RELB (21). This indirectly activates NF- $\kappa \mathrm{B}$ signaling. Constitutive NF- $\kappa \mathrm{B}$ activation mediated by MALT1 protease activity is observed in the ABC-DLBCL subtype and is linked to its pathogenesis. Inhibition of MALT1 protease activity or expression of a catalytically inactive form of MALT1 dramatically reduced the viability of cell lines derived from ABC-DLBCL, while cell lines derived from other B cell 
lymphoma types, such as GCB-DLBCL, Burkitt's lymphoma, and marginal zone lymphoma, were not affected (22). Recently, small molecule inhibitors of MALT1 were developed that efficiently suppressed ABC-DLBCL in xenograft experiments and patient samples ex vivo (23). These evidences indicate that MALT1 protease activity is required for the survival of ABC-DLBCL but not GCB-DLBCL. Although PD-L1 expression is regulated by NF- $\kappa \mathrm{B}$ in cancer cells (24), it remains an open question whether MALT1 protease activity regulates $\mathrm{PD}-\mathrm{L} 1$ expression and the PD-L1-mediated immune-evasion in ABC-DLBCL.

In this study, we report that MALT1 protease activity is essential for PD-L1 expression in ABC-DLBCL cells under V $\gamma 9$ V $82 \mathrm{~T}$ lymphocytes stress. We found that MALT1 protease activity supported glutaminolysis by up-regulating expression of the enzyme GLS1, resulting in higher glutamate production. Subsequently, glutamate enters the TCA cycle to enhance STAT3 activation and PD-L1 expression. Thus, MALT1 protease activity supports glutaminolysis and contributes to ABC-DLBCL cell immune evasion.

\section{MATERIALS AND METHODS}

\section{Cell Culture and Reagents}

The human DLBCL cell lines BJAB, U2932, OCI-Ly3 were obtained from DSMZ, SUDHL-4, and SUDHL-6 were obtained from American Type Culture Collection (ATCC; Manassas, VA, USA). All cell lines were cultured in RPMI 1640 medium supplemented with $20 \%$ FBS and $100 \mathrm{U} / \mathrm{ml}$ penicillin/streptomycin (Gibco). OCI-Ly10 was purchased from Cobioer Biosciences Co., LTD (Nanjing, China) and cultured in IMDM with $20 \% \mathrm{FBS}, 100 \mathrm{U} / \mathrm{ml}$ penicillin/streptomycin (Gibco) and $50 \mu \mathrm{M} \beta$-mercaptoethanol (Sigma-Aldrich). All cell lines were cultured at $37^{\circ} \mathrm{C}$ in a humidified atmosphere of $5 \% \mathrm{CO}_{2}$.

z-VRPR-fmk (Enzo Life Sciences) was dissolved in $\mathrm{dd}_{2} \mathrm{O}$ at a concentration of $50 \mu \mathrm{M}$ throughout all experiments. MI-2, BPTES, QNZ, CPI-613 (Selleck), and PMA/Iono (Sigma-Aldrich) were reconstituted in DMSO (final DMSO concentration 0.1\%) and their final concentrations were $1 \mu \mathrm{M}, 2 \mu \mathrm{M}, 5 \mu \mathrm{M}, 100 \mu \mathrm{M}$, and $50 / 500 \mathrm{ng} / \mathrm{ml}$, respectively.

\section{Generation of $\mathrm{V} \gamma \mathbf{9} \mathbf{V} \delta \mathbf{2} \mathrm{T}$ Lymphocytes}

PBMCs from fresh blood samples of healthy adult donors were isolated using density gradient centrifugation with FicollPaque (GE Healthcare). To generate V $\gamma 9 \mathrm{~V} \delta 2 \mathrm{~T}$ lymphocytes, freshly isolated PBMCs were cultured in RPMI 1640 medium supplemented with $10 \%$ heat-inactivated FBS, $100 \mathrm{U} / \mathrm{ml}$ penicillin/streptomycin (Gibco) and $50 \mu \mathrm{M} \beta$-mercaptoethanol at a density of $3 \times 10^{6}$ cells $/ \mathrm{mL}$ in a 24 -well plate. At the onset of the culture, $30 \mu \mathrm{M}$ zoledronic acid (Sigma-Aldrich) and $400 \mathrm{U} / \mathrm{mL}$ IL-2 (PeproTech, Inc.) were added. Three days later, the medium was replaced with maintenance medium

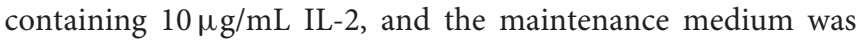
changed every 2-3 days. The cells were selectively expanded after 10-14 days. This study was carried out in accordance with the recommendations of local ethics guidelines, the Ethics committee of Jinan University with written informed consent from all subjects. All subjects gave written informed consent in accordance with the Declaration of Helsinki. The protocol was approved by the Ethics committee of Jinan University. Experimental procedures have been carried out following the standard biosecurity and the institutional safety procedures.

\section{Cytotoxicity Assay}

The cytotoxic potential of expanded V $\gamma 9 \mathrm{~V} \delta 2 \mathrm{~T}$ lymphocytes against DLBCL cells was assayed using propidium iodide (PI, Sangon Biotech Shanghai Co., Ltd.) staining. In brief, CFSE-labeled V $\gamma 9 \mathrm{~V} \delta 2 \mathrm{~T}$ lymphocytes were co-incubated with DLBCL cells at different effector:target (E:T) ratios of $\mathrm{V} \gamma 9 \mathrm{~V} \delta 2 \mathrm{~T}$ lymphocytes to DLBCL cells $(0: 1,5: 1,10: 1$, and $20: 1)$ at $37^{\circ} \mathrm{C}$ for $6 \mathrm{~h}$. After cells were washed with PBS, PI solution was added to the co-culture and incubated with the cells for $5 \mathrm{~min}$. Subsequently, the proportion of $\mathrm{PI}^{+} \mathrm{CFSE}^{-}$cells was quantified using flow cytometry. In some experiments, DLBCL cells were pretreated with z-VRPR-fmk, BPTES or QNZ for $12 \mathrm{~h}$ prior to co-culture with $\mathrm{V} \gamma 9 \mathrm{~V} \delta 2 \mathrm{~T}$ lymphocytes. For blocking assays, purified anti-human CD274 antibody $(10 \mu \mathrm{g} / \mathrm{ml}$; 29E.2A3) or isotype control antibody (10 $\mathrm{g} / \mathrm{ml}$; MG2b-57; BioLegend) were included at the time of effector/target co-culture.

\section{Real-Time RT-PCR}

Total RNA was extracted with an RNA Simple Total RNA kit (Tiangen Biotech Beijing Co., Ltd.). Synthesis of cDNA was performed with DNA-free RNA samples (Qiagen) using reverse transcription with abPrimeScript ${ }^{\mathrm{TM}}$ RT reagent kit (Takara) according to the manufacturer's protocol. Real-time PCR was performed using SYBR Green qPCR Master Mix (Bimake) on a LC480 Lightcycler system (Roche). RNA was normalized to $\beta$ actin mRNA. The sequences of primers were as follows $\left(5^{\prime}\right.$ to $3^{\prime}$ ): (forward) TTC GGT CCA GTT GCC TTCT and (reverse) GGT GAG TGG CTG TCT GTG TG for IL-6, (forward) TGG GGG AGA ACC TGA AGA and (reverse) ATG GCT TTG TAG ATG CCT TTC for IL-10, (forward) GTG AGT CGG ATC GCA GCTT and (reverse) TCG GCT GCT GCA TTG TTC for Bal$\mathrm{xl}$, (forward) CAT GTA CGT TGC TAT CCA GGC and (reverse) CTC CTT AA TGTC ACG CAC GAT for $\beta$-actin.

\section{Flow Cytometry}

To measure the proportion and differential subsets of $\mathrm{V} \gamma 9 \mathrm{~V} \delta 2 \mathrm{~T}$ lymphocytes, we performed surface staining with FITCconjugated anti-CD3 (Tianjin Sungene Biotech Co., Ltd.), PerCP-conjugated anti-TCR V $\delta 2$, Pacific Blue-conjugated anti-CD27 and APC-conjugated anti-CD45RA (BioLegend) antibodies. To evaluate the functional markers of $\mathrm{V} \gamma 9 \mathrm{~V} \delta 2 \mathrm{~T}$ lymphocytes, cells were restimulated with $50 \mathrm{ng} / \mathrm{ml}$ PMA and $500 \mathrm{ng} / \mathrm{ml}$ ionomycin for $6 \mathrm{~h}$, permeabilized using reagents from a BD Cytofix/Cytoperm Kit and stained with PE-Cy7conjugated anti-NKG2D, APC-conjugated anti-IFN- $\gamma$ (BD Biosciences), PE-conjugated anti-Perforin and Pacific Blueconjugated anti-Granzyme B (BioLegend) antibodies. GolgiStop (BD Biosciences) was added for the last $4 \mathrm{~h}$ of culture. To evaluate intracellular protein, DLBCL cells were sorted from the co-culture, fixed, permeabilized using BD Phosflow ${ }^{\mathrm{TM}}$ (BD Biosciences) and stained with Alexa Fluor ${ }^{\circledR}$ 647-conjugated 
anti-STAT3 Phospho (Tyr705) (Biolegend). To measure PD-L1 ${ }^{+}$ or $\mathrm{PD}^{+}{ }^{+}$cells, V $\gamma 9 \mathrm{~V} \delta 2 \mathrm{~T}$ lymphocytes were co-incubated with DLBCL cells for $6 \mathrm{~h}$. We then performed surface staining with BV421-conjugated anti-PD-L1 (Biolegend) or Pacific Blue-conjugated anti-PD-1 (Biolegend) antibodies. For the cell survival assay, an Annexin V/PI apoptosis kit (Bimake) was used. The data were analyzed using FlowJo software (Tree Star, $\operatorname{lnc})$.

\section{Western Blotting}

Cell pellets were collected after washing with PBS. Total cellular protein was extracted using lysis buffer $(20 \mathrm{mM}$ Tris$\mathrm{HCl}(\mathrm{pH}$ 7.4), $150 \mathrm{mM} \mathrm{NaCl}, 1 \mathrm{mM}$ EDTA, $1 \mathrm{mM}$ EGTA, $1 \%$ Triton X-100, $2.5 \mathrm{mM}$ sodium pyrophosphate, $1 \mathrm{mM}$ $\beta$-glycerophosphate, $1 \mathrm{mM}$ sodium orthovanadate, $1 \mu \mathrm{g} / \mathrm{ml}$ leupeptin, $1 \mathrm{mM}$ phenylmethylsulfonyl fluoride), and the protein concentration was determined with a BCA Kit (Pierce). After boiling in SDS-PAGE loading buffer, 20-40 $\mu \mathrm{g}$ of protein in total cell lysates was fractionated via SDS-PAGE and transferred to PVDF membranes (Millipore). Blots were blocked in 5\% BSA (Sigma-Aldrich) and incubated with the appropriate antibodies. The primary antibodies anti-Bcl-10, anti-RelB, anti-p65/Phospho-p65, anti-AKT/Phospho-AKT, anti-ERK/Phospho-ERK, anti-STAT3/Phospho-STAT3 (Cell Signaling), anti-Bcl-xl (Proteintech), anti-GLS1, anti-VDAC1 (Sangon Biotech Shanghai Co., Ltd.), and anti- $\beta$-actin (Tianjin Sungene Biotech Co., Ltd.) were used. Goat-anti-mouse IgG/HRP and goat-anti-rabbit IgG/HRP (Cell Signaling) were the secondary antibodies used. The data were acquired using a ChemiDoc ${ }^{\text {TM }}$ XRS + System (Bio-Rad) with enhanced chemiluminescence HRP substrate (Millipore).

\section{Seahorse}

OCR and ECAR were assessed using a Seahorse XF-96 extracellular flux analyzer (Seahorse Bioscience). DLBCL cells were pooled, carefully counted and plated $\left(1 \times 10^{5}\right.$ cells/well $)$ in assay medium onto Seahorse cell plates coated with CellTak (Corning, Inc.). For OCR, assay medium was supplied with XF Base Medium with $1 \mathrm{mM}$ pyruvate, $2 \mathrm{mM}$ glutamine, and $10 \mathrm{mM}$ glucose (Sigma-Aldrich). Baseline OCR was defined as the OCR readings before $1 \mu \mathrm{M}$ oligomycin (Seahorse Bioscience) injection. SRC was defined as the difference between baseline OCR and maximal OCR after carbonyl cyanide-4(trifluoromethoxy) phenylhydrazone (FCCP, $0.5 \mu \mathrm{M}$, Seahorse Bioscience) injection to uncouple oxidative phosphorylation and electron transport. For ECAR, assay medium was supplied with XF Base Medium with $2 \mathrm{mM}$ glutamine. Glycolysis was defined as the ECAR reached by a given cell after the addition of saturating amounts of glucose. Glycolytic reserve was defined as the difference in ECAR between the glucose and $1 \mu \mathrm{M}$ oligomycin injections.

\section{Confocal Microscopy}

Treated DLBCL cell lines were washed with RPMI 1640 medium without phenol red and stained with MitoTracker Green (ThermoFisher) for $30 \mathrm{~min}$ at $37^{\circ} \mathrm{C}$. After washing, cells were resuspended with $\mathrm{PBS}$ and dropped in a glass slides, cover-slipped with a fluoroshield mounting medium with DAPI (Abcam). Images were collected on a Leica TCS SP8 confocal microscopy.

\section{Mitochondria Isolation and Mitochondrial ATP Assay}

Mitochondria isolation was performed using Qproteum mitochondria isolation kit as manufacturer' protocol (Qiagen, USA). The ATP assay kit was from Beyotime and the assay was performed according to manufacturer's protocol. After centrifugation to remove cell debris, the supernatant was added to the substrate solution. The luminescence was recorded in an Illuminometer with an integration time of $10 \mathrm{~s}$ per well.

\section{Analysis of [U- $\left.{ }^{13} \mathrm{C}\right]-$ Glucose Metabolites and Glutamate Assay}

$\mathrm{U} 2932$ cells were grown in $\left[\mathrm{U}_{-}{ }^{13} \mathrm{C}\right]$-glucose medium and were treated with $\mathrm{z}$-VRPR-fmk or not for $12 \mathrm{~h}$. After collection, $1 \mathrm{~mL}$ of chloroform and $1 \mathrm{~mL}$ of methanol $/ \mathrm{H}_{2} \mathrm{O}$ solvent $(\mathrm{v} / \mathrm{v}=1: 1)$ were successively added into a tube of cells. The suspension was vortexed for $30 \mathrm{~s}$ and incubated at $4^{\circ} \mathrm{C}$ for $2 \mathrm{~h}$. The mixture was processed using 7 cycles of ultrasonication for $2 \mathrm{~min}$ and incubated at $-40^{\circ} \mathrm{C}$ for $2 \mathrm{~min}$ before centrifugation at 16 , $000 \mathrm{~g}$ and $4^{\circ} \mathrm{C}$ for $15 \mathrm{~min}$. In total, $400 \mu \mathrm{L}$ of supernatant was transferred into a glass vial containing $10 \mu \mathrm{L}$ of internal standards (0.05 mg/mL 13C6-15N-L-isoleucine), and dried under a gentle nitrogen stream. The dry residues were reconstituted in $30 \mu \mathrm{L}$ of $15 \mathrm{mg} / \mathrm{mL}$ methoxylamine hydrochloride in anhydrous pyridine. The resulting mixture was vortex-mixed vigorously for $30 \mathrm{~s}$ and incubated at $37^{\circ} \mathrm{C}$ for $90 \mathrm{~min}$. Then, $30 \mu \mathrm{L}$ of MTBSTFA (with $1 \%$ BDMCS) was added to the mixture and derivatized at $55^{\circ} \mathrm{C}$ for $60 \mathrm{~min}$. Metabolomic instrumental analysis was performed on an Agilent 7890A gas chromatography system coupled to an Agilent 5975C inert MSD system (Agilent Technologies Inc.). An HP$5 \mathrm{~ms}$ fused-silica capillary column $(30 \mathrm{~m} \times 0.25 \mathrm{~mm} \times 0.25 \mu \mathrm{m}$; Agilent J\&W Scientific, Folsom, CA) was utilized to separate the derivatives. Helium ( $>99.999 \%$ ) was used as a carrier gas at a constant flow rate of $1 \mathrm{~mL} / \mathrm{min}$ through the column. The injection volume was $1 \mu \mathrm{L}$ (splitless mode), and the solvent delay time was $5.5 \mathrm{~min}$. The initial oven temperature was held at $100^{\circ} \mathrm{C}$ for $2 \mathrm{~min}$, ramped to $140^{\circ} \mathrm{C}$ at a rate of $10^{\circ} \mathrm{C} / \mathrm{min}$, to $260^{\circ} \mathrm{C}$ at a rate of $5^{\circ} \mathrm{C} / \mathrm{min}$, to $320^{\circ} \mathrm{C}$ at a rate of $10^{\circ} \mathrm{C} / \mathrm{min}$, and finally held at $320^{\circ} \mathrm{C}$ for $8 \mathrm{~min}$. The temperatures of the injector, transfer line, and electron impact ion source were set to $250^{\circ} \mathrm{C}, 250^{\circ} \mathrm{C}$, and $230^{\circ} \mathrm{C}$, respectively. The electron energy was $70 \mathrm{eV}$, and data were collected in full scan mode (m/z 50-600). At least three separate injections were measured per sample, and the percent enrichment of ${ }^{13} \mathrm{C}$-labeled metabolites in the total metabolite pool was calculated for each metabolite.

Glutamate assays were performed according to the manufacturer's protocols (Sigma-Aldrich).

\section{Statistical Analysis}

Two-tailed, unpaired or paired Student's $t$-test was used to compare differences between treated and control groups using GraphPad Prism 6.0 software. Differences with $p$-values $<0.05$ were considered statistically significant: ${ }^{*} p<0.05$; ${ }^{* *} p<0.01$; *** $p<0.001$. 
A

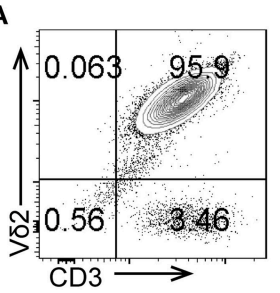

B

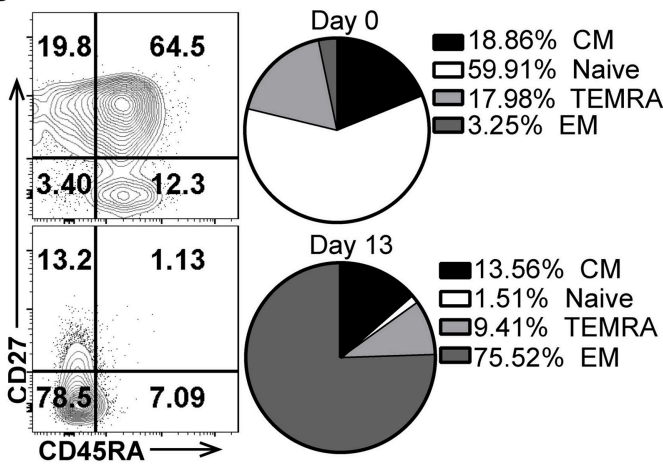

c

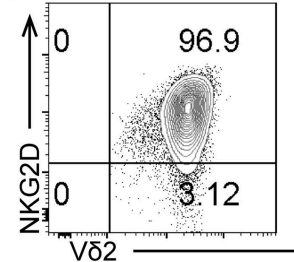

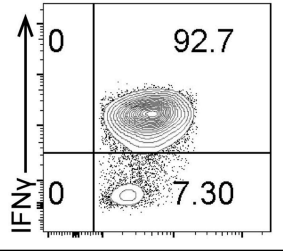

D

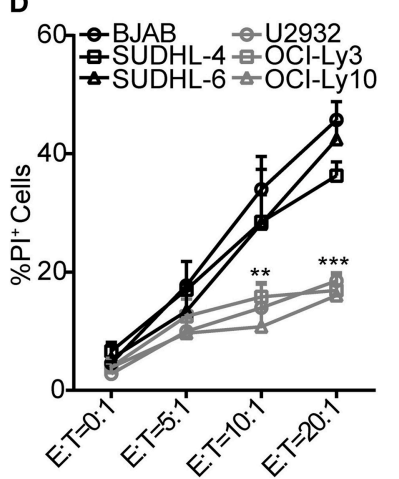

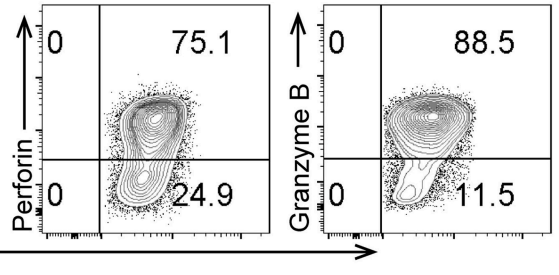

E

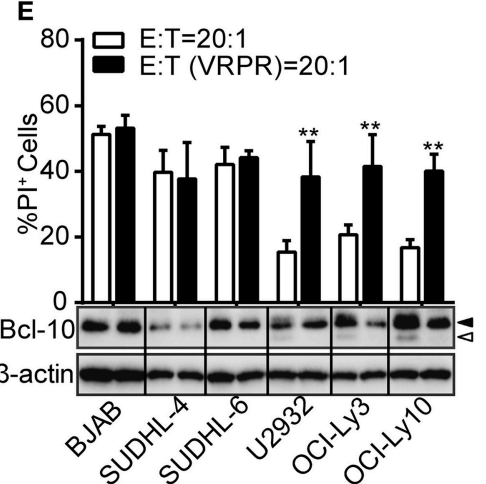

$\mathbf{F}$
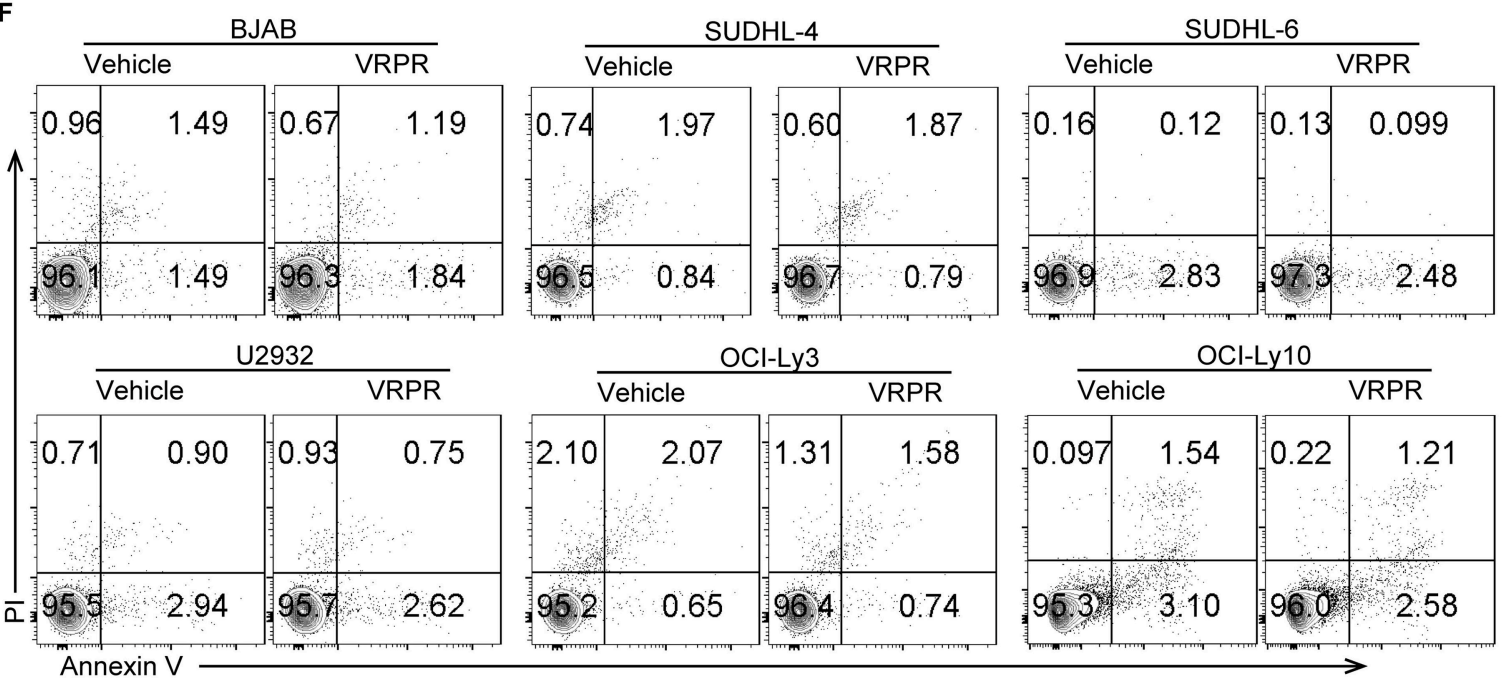

FIGURE 1 | MALT1 protease activity is required for ABC-DLBCL cell escape from the cytotoxicity of human $V \gamma 9 \mathrm{~V} \delta 2 \mathrm{~T}$ lymphocytes. (A) The purity of $\mathrm{V} \gamma \mathrm{V} \mathrm{V} \delta 2 \mathrm{~T}$ lymphocytes expanded in vitro on day 13. (B) Differentiation subsets of $\mathrm{V} \gamma 9 \mathrm{~V} \delta 2 \mathrm{~T}$ lymphocytes on day 0 and day $13 . \mathrm{V} \gamma 9 \mathrm{~V} \delta 2 \mathrm{~T}$ lymphocyte subsets were subdivided according to CD27 and CD45RA expression: naiive (CD45RA $\left.{ }^{+} \mathrm{CD} 27^{+}\right)$, CM $\left(\mathrm{CD}_{4}\right.$ RAA $\left.{ }^{-} \mathrm{CD} 27^{+}\right)$, EM $\left(\mathrm{CD} 45 \mathrm{RA}^{-} \mathrm{CD}^{-} 7^{-}\right)$, and TEMRA $\left(\mathrm{CD} 45 \mathrm{RA}^{+} \mathrm{CD} 27^{-}\right)(n=5)$. (C) The percentage of $\mathrm{NKG}_{2} \mathrm{D}^{+}$, IFN- $\gamma^{+}$, perforin ${ }^{+}$and Granzyme $\mathrm{B}^{+}$cells within the $\mathrm{V} \gamma \mathrm{V} \delta 2 \mathrm{~T}$ lymphocyte population. (D) Cytotoxicity of $\mathrm{V} \gamma \mathrm{V} \delta 2 \mathrm{~T}$ lymphocytes toward DLBCL cells at the indicated effector to target ratios $(\mathrm{E}: \mathrm{T})(n=5)$. (E) Cytotoxicity of $\mathrm{V} \gamma 9 \mathrm{~V} \delta 2 \mathrm{~T}$ lymphocytes toward DLBCL cells pretreated with vehicle or z-VRPR-fmk (VRPR) for $12 \mathrm{~h}(n=5)$. Western blot to detect Bcl-10 cleavage products; Filled arrow, full length Bcl-10; open arrow, Bcl-10 cleavage product; $\beta$-actin was used as the loading control. (F) Survival of DLBCL cells pretreated with vehicle or VRPR for $12 \mathrm{~h}$ followed by apoptosis analysis via flow cytometry. The data are representative of three independent experiments. Data are shown as the means $\pm S D,{ }^{* *} p<0.01 ;{ }^{* \star *} p<0.001$.

\section{RESULTS}

\section{MALT1 Protease Activity Is Required for ABC-DLBCL Cell Escape From the Cytotoxicity of Human $V_{\gamma} 9 \mathrm{~V} \delta 2 \mathrm{~T}$ Lymphocytes}

To investigate whether ABC-DLBCL and GCB-DLBCL cells exert different immune-evasion effects on $\mathrm{T}$ lymphocytes, we expanded $\mathrm{V} \gamma 9 \mathrm{~V} \delta 2 \mathrm{~T}$ lymphocytes by culturing human peripheral blood mononuclear cells (PBMCs) from healthy adults and co-cultured them with three ABC-DLBCL cell lines (U2932, OCI-Ly3, and OCI-Ly10) and three GCB-DLBCL cell lines (BJAB, SUDHL-4, and SUDHL-6) in vitro. Expanded V $\gamma 9 \mathrm{~V} \delta 2 \mathrm{~T}$ lymphocytes typically accounted for more than $95 \%$ of the cultured PBMCs (Figure 1A) and were mainly effector memory $\left(\mathrm{EM}, \mathrm{CD} 45 \mathrm{RA}^{-} \mathrm{CD}^{-} 7^{-}\right)$cells, which displayed efficient cytotoxic 
activity and cytokine production (Figure 1B). Flow cytometric analysis confirmed that the expanded $\mathrm{V} \gamma 9 \mathrm{~V} \delta 2 \mathrm{~T}$ lymphocytes expressed the innate receptor NKG2D and produced IFN- $\gamma$, the cytolytic protein perforin, and granzyme B (Figure 1C). As expected, ABC-DLBCL cells showed fewer $\mathrm{PI}^{+}$populations than GCB-DLBCL cells when selected by $\mathrm{V} \gamma 9 \mathrm{~V} \delta 2 \mathrm{~T}$ lymphocytes at the various $\mathrm{E} / \mathrm{T}$ ratios tested (Figure $1 \mathrm{D}$ ), suggesting that $\mathrm{ABC}$ DLBCL cells were more inclined to subvert the cytotoxicity of V $\gamma 9$ V $82 \mathrm{~T}$ lymphocytes. To further illustrate whether MALT1 protease activity is involved in the tolerance of ABC-DLBCL cells to $\mathrm{V} \gamma 9 \mathrm{~V} \delta 2 \mathrm{~T}$ lymphocytes, we pretreated DLBCL cell lines with z-VRPR-fmk, a cell-permeable and irreversible MALT1 inhibitor. z-VRPR-fmk treatment efficiently blocked the proteolytic activity of MALT1, as indicated by the absence of the cleavedBCL10 fragment (Figure 1E). Interestingly, all three z-VRPRfmk pretreated ABC-DLBCL cell lines doubled their cell death in response to $\mathrm{V} \gamma 9 \mathrm{~V} \delta 2 \mathrm{~T}$ lymphocytes (Figure 1E). In stark contrast, $\mathrm{z}$-VRPR-fmk did not have a significant effect on any of the three GCB-DLBCL cell lines tested (Figure 1E). Moreover, zVRPR-fmk alone had no impact on the survival of these DLBCL cells (Figure 1F). These results indicated that MALT1 protease activity has an essential role in assisting ABC-DLBCL cell escape from the cytotoxicity of $\mathrm{V} \gamma 9 \mathrm{~V} \delta 2 \mathrm{~T}$ lymphocytes.

\section{PD-L1 Is Involved in the MALT1 Protease Activity-mediated Immunosuppressive Property of ABC-DLBCL Cells}

To confirm that PD-L1 plays a key role in ABC-DLBCL cell resistance to the cytotoxicity of $\mathrm{V} \gamma 9 \mathrm{~V} \delta 2 \mathrm{~T}$ lymphocytes, we screened a panel of DLBCL cell lines for PD-L1 expression using flow cytometry. Surprisingly, only the OCI-Ly10 cell line showed high levels of PD-L1 expression. The others, including three GCB-DLBCL cell lines (BJAB, SUDHL-4 and SUDHL-6) and two ACB-DLBCL cell lines (U2932 and OCILy3), expressed little PD-L1 (Figure 2A). Considering that PDL1 expression is immunologically active by suppressing the activation of tumor-associated $\mathrm{T}$ cells $(9,25)$, we checked the kinetics of PD-L1 expression on these DLBCL cell lines in response to $\mathrm{V} \gamma 9 \mathrm{~V} \delta 2 \mathrm{~T}$ lymphocytes. We observed that the proportion of $\mathrm{PD}-\mathrm{L1}^{+}$cells increased in the DLBCL cell lines, suggesting that $\mathrm{V} \gamma 9 \mathrm{~V} \delta 2 \mathrm{~T}$ lymphocyte stress might promote PD-L1 expression (Figure 2B). Interestingly, the proportion of $\mathrm{PD}_{-\mathrm{L} 1}{ }^{+} \mathrm{ABC}-\mathrm{DLBCL}$ cells was generally higher than that of PD-L1 ${ }^{+}$GCB-DLBCL cells. Treatment with z-VRPRfmk significantly decreased the proportion of $\mathrm{PD}-\mathrm{L}^{+} \mathrm{ABC}$ DLBCL cells (Figure 2B). These results revealed that MALT1 protease activity is essential for PD-L1 expression on ABCDLBCL cells. Importantly, blocking PD-L1 with anti-PD-L1 antibodies effectively restored the cytotoxicity of $\mathrm{V} \gamma 9 \mathrm{~V} \delta 2 \mathrm{~T}$ lymphocytes (Figure 2C). In addition, administration of antiPD-L1 antibody induced no further increase in cytotoxicity when combined with $z$-VRPR-fmk, suggesting that z-VRPRfmk enhances V $\gamma 9 \mathrm{~V} \delta 2 \mathrm{~T}$ lymphocyte cytotoxicity toward ABCDLBCL cells mainly by inhibiting PD-L1 expression (Figure 2C). On the other hand, we found that an average of $\sim 20 \%$ of the expanded V $\gamma 9 \mathrm{~V} \delta 2 \mathrm{~T}$ lymphocytes expressed PD-1 in the basal state (Figure 2D). The proportion remained nearly the same when V $\gamma 9 \mathrm{~V} \delta 2 \mathrm{~T}$ lymphocytes were incubated with GCBDLBCL cells, but markedly increased when they were mixed with ABC-DLBCL cells (Figures 2E,F). However, the PD-1 expression remained unchanged in $\mathrm{V} \gamma 9 \mathrm{~V} \delta 2 \mathrm{~T}$ lymphocytes incubated with GCB-DLBCL or ABC-DLBCL cells pretreated with z-VRPR-fmk (Figures 2E,F). Together, these data support the idea that $\mathrm{z}$ VRPR-fmk selectively decreases the generation of PD-L1 ${ }^{+} \mathrm{ABC}-$ DLBCL cells in response to $\mathrm{V} \gamma 9 \mathrm{~V} \delta 2 \mathrm{~T}$ lymphocytes, thereby inhibiting the immunosuppressive property of ABC-DLBCL cells.

\section{NF-kB Is Dispensable for PD-L1+ ABC-DLBCL Cells Generation Mediated by MALT1 Protease Activity}

$\mathrm{NF}-\kappa \mathrm{B}$, a common transcription factor downstream of the CBM complex, has been shown to regulate PD-L1 expression in tumor cells $(24,26)$. Thus, we assessed whether NF- $\kappa \mathrm{B}$ is indispensable for the PD-L1 expression on ABC-DLBCL cells mediated by MALT1 protease activity. We found that NF- $\kappa$ B transcription activity was significantly inhibited in ABC-DLBCL cells based on the diminished expression of NF- $\kappa \mathrm{B}$ target genes, including $\mathrm{Bcl}$-xl protein expression (Figure 3A) and the mRNA levels of Bcl-xl, IL-6, and IL-10 (Figure 3B), in response to Z-VRPRfmk treatment. However, the abolished NF- $\kappa$ B transcription activity induced by $\mathrm{z}$-VRPR-fmk recovered in the presence of $\mathrm{V} \gamma 9 \mathrm{~V} \delta 2 \mathrm{~T}$ lymphocytes (Figures $3 \mathbf{A}, \mathbf{B}$ ). We excluded the possibility that $z$-VRPR-fmk lost its NF- $\kappa \mathrm{B}$ inhibition activity by including $\mathrm{BJAB}$ cells as a negative control; in these cells, NF$\kappa B$ target genes remained constant under these conditions. Since the proportion of PD-L1 ${ }^{+}$ABC-DLBCL cells was profoundly decreased by z-VRPR-fmk (Figure 2B), NF- $\mathrm{B}$ might not be involved in the $\mathrm{PD}-\mathrm{L1}^{+} \mathrm{ABC}-\mathrm{DLBCL}$ cell generation under the stress of $\mathrm{V} \gamma 9 \mathrm{~V} \delta 2 \mathrm{~T}$ lymphocytes. To confirm the role of NF- $\mathrm{B}$ in generating $\mathrm{PD}-\mathrm{L} 1^{+} \mathrm{ABC}-\mathrm{DLBCL}$ cells, we directly blocked NF- $\kappa B$ transcription using QNZ. Distinct from $z$-VRPR-fmk, QNZ completely blocked NF- $\kappa \mathrm{B}$ transcription under $\mathrm{V} \gamma 9 \mathrm{~V} \delta 2 \mathrm{~T}$ lymphocyte stress, as shown by the extreme decreases in $\mathrm{Bcl}-\mathrm{xl}$ protein expression (Figure 3C) and the Bcl-xl, IL-6, and IL-10 mRNA levels (Figure 3D). Importantly, QNZ-induced blockage of NF- $\kappa \mathrm{B}$ transcription activity only slightly increased cell death in ABC-DLBCL cells (Figure 3E) and slightly decreased PD$\mathrm{L1}^{+} \mathrm{ABC}-\mathrm{DLBCL}$ cell generation (Figure 3F). Taken together, $\mathrm{NF}-\kappa \mathrm{B}$ is dispensable for the generation of PD-L1 ${ }^{+} \mathrm{ABC}-\mathrm{DLBCL}$ cells mediated by MALT1 protease activity under $\mathrm{V} \gamma 9 \mathrm{~V} \delta 2 \mathrm{~T}$ lymphocyte stress.

\section{MALT1 Protease Activity Endowed ABC-DLBCL Cells With Latent Mitochondrial Bioenergetics Ability}

A possible link was recently reported between metabolic alterations and PD-L1 expression $(18,19)$. Hence, we proposed that MALT1 protease activity might be involved in regulating cell metabolic reprogramming to support $\mathrm{PD}-\mathrm{L}^{+}{ }^{+} \mathrm{ABC}-\mathrm{DLBCL}$ cell generation. To test our hypothesis, we examined the bioenergetic profiles of z-VRPR-fmk- or vehicle-treated DLBCL cells, after 


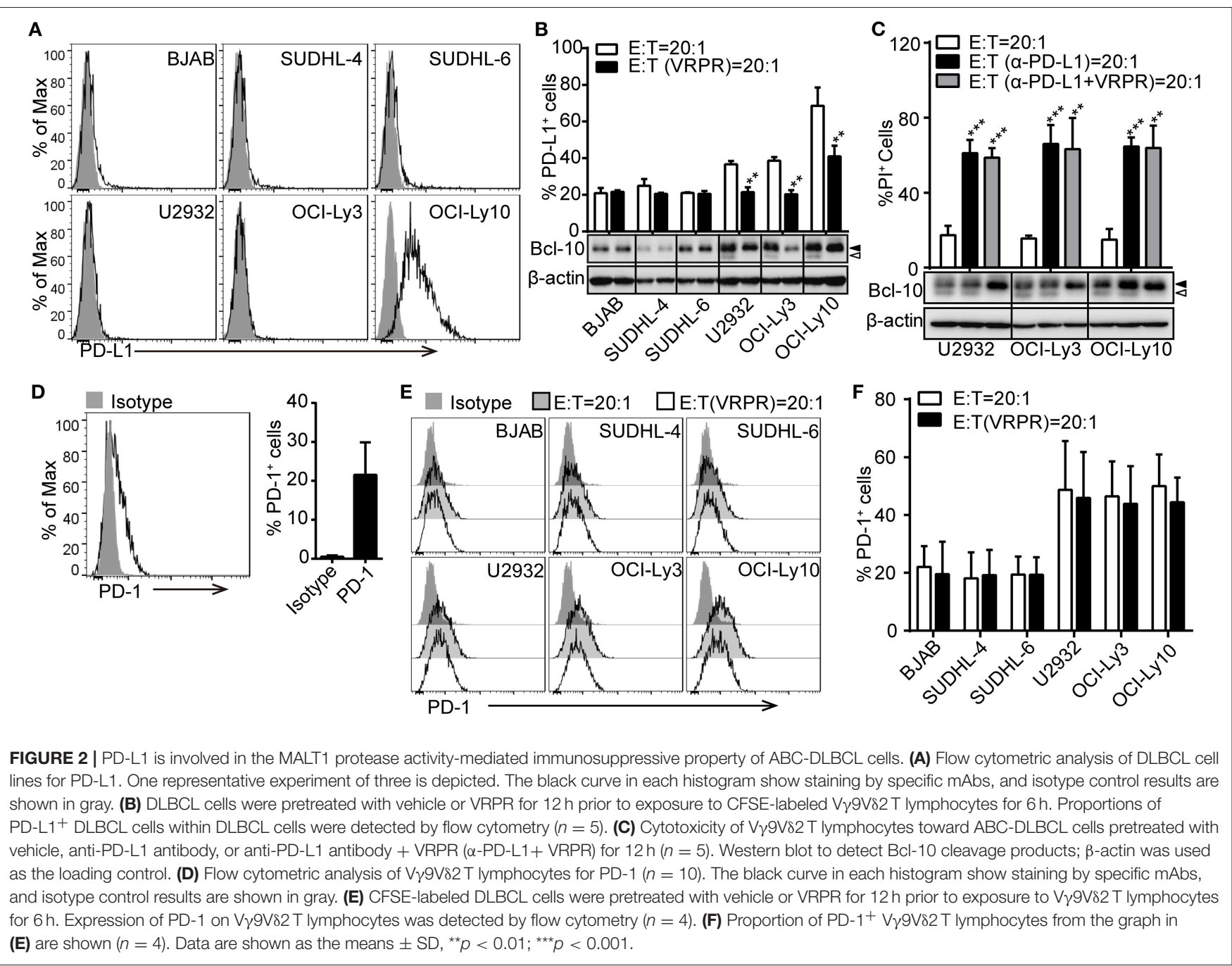

confirming z-VRPR-fmk efficiently blocked the proteolytic activity of MALT1 (Supplementary Figure 1A). We found that the basal oxygen consumption rate (OCR) was slightly lower in ABC-DLBCL cells primed with z-VRPR-fmk, while mitochondrial spare respiratory capacity (SRC) was substantially decreased, as revealed through the difference between basal OCR and maximal OCR after FCCP treatment (Figures 4A,B). This absent mitochondrial SRC suggested that mitochondria in these cells were operating close to their bioenergetics limit under stressful conditions, which was further confirmed by decreased ATP-coupled OCR and mitochondrial ATP levels (Supplementary Figure 1B). However, mitochondria biogenesis was not influenced by VRPR, which was indicated by unchanged VDAC1 protein levels and intensity of MitoTracker Green staining (Supplementary Figures 1C,D). For GCB-DLBCL cells, these were not influenced by treatment with z-VRPR-fmk (Figures 4C,D; Supplementary Figures 1B-D). Furthermore, we found that GCB-DLBCL cells (BJAB and SUDHL-4 cells) with activated MALT1 protease activity presented higher basal OCR and mitochondrial SRC than the control group or the z-VRPR-fmk combined with PMA/Iono group
(Supplementary Figure 2A; Figures 4E,F). We also measured the changes in extracellular acidification rate (ECAR), a typical readout of cellular glycolytic activity, in these DLBCL cells by administering $\quad \mathrm{Z}$-VRPR-fmk (Supplementary Figures 2B,C). The data were analyzed and reported as the rate of glycolysis under basal conditions and glycolytic reserve calculated as the difference between the maximal glycolytic capacity and the basal glycolysis, which revealed unchanged after z-VRPR-fmk treatment (Supplementary Figures 2D,E). All the above data showed that MALT1 protease activity endowed ABC-DLBCL cells with a latent ability for mitochondrial bioenergetics, which might be fully applied in response to $\mathrm{V} \gamma 9 \mathrm{~V} \delta 2$ T lymphocytes.

\section{MALT1 Protease Activity-supported Mitochondrial Bioenergetics Is Dependent on Glutaminolysis}

To understand how MALT1 protease activity supports mitochondrial bioenergetics in ABC-DLBCL cells, we analyzed the metabolic consequences in the U2932 cell line, whose 


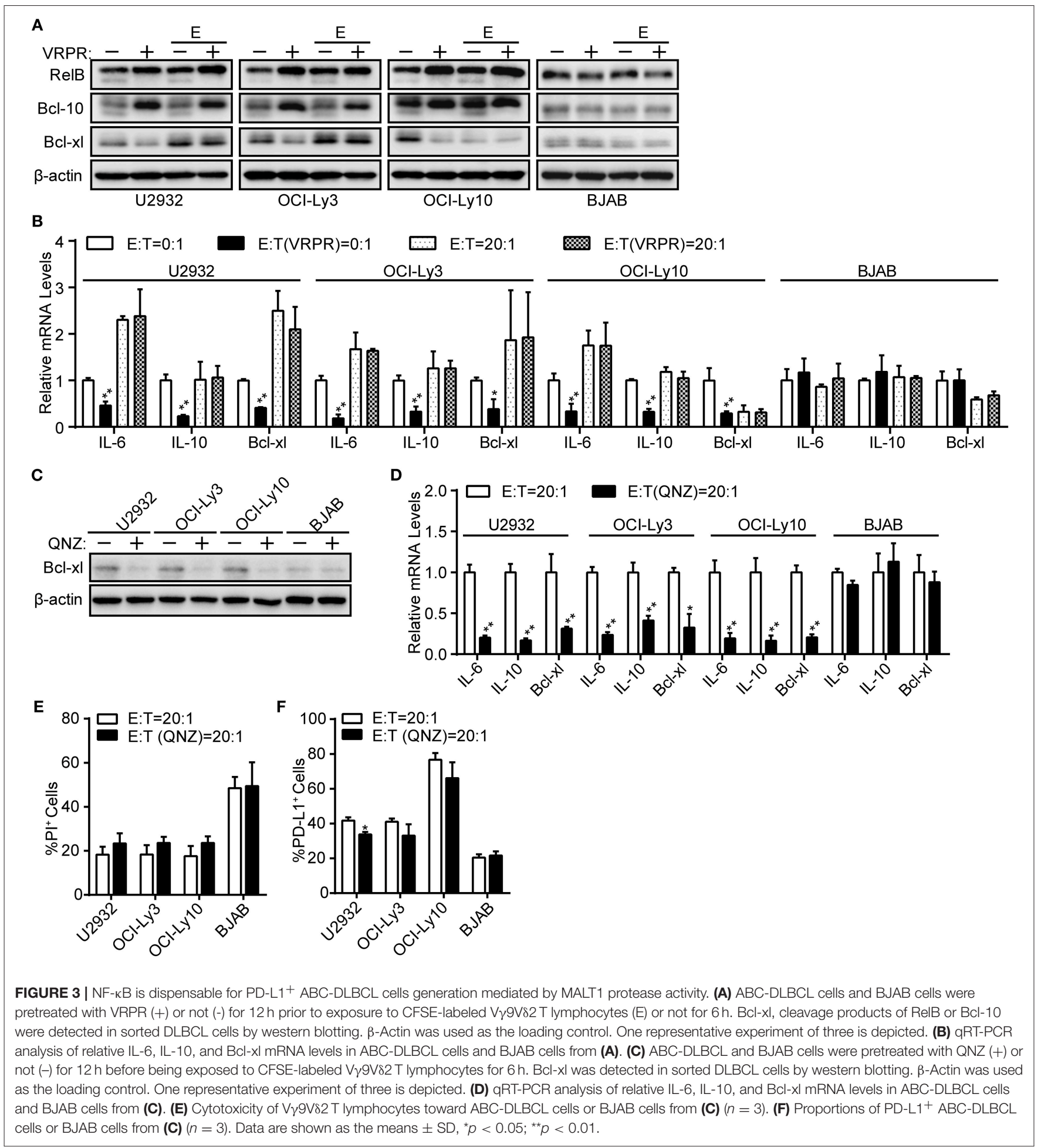

MALT1 protease activity was profoundly blocked by z-VRPRfmk (Supplementary Figure 3A). We grew these cells in uniformly labeled $\left[\mathrm{U}_{-}{ }^{13} \mathrm{C}\right]$-glucose medium. As the results showed, there was no change in the level of the $\mathrm{m}+3$ isotopolog of lactate $\left({ }^{13} \mathrm{C}_{3}\right.$-lactate $)$ derived from $\left[\mathrm{U}_{-}{ }^{13} \mathrm{C}\right]$-glucose, which indicated an unchanged ECAR of ABC-DLBCL cells primed with $z$-VRPR-fmk (Figure 5A). In addition, z-VRPR-fmk did not impact pyruvate derived from $\left[\mathrm{U}_{-}{ }^{13} \mathrm{C}\right]$-glucose $(\mathrm{m}+3$ forms). However, glucose-derived TCA cycle intermediates, such as the doubly ${ }^{13} \mathrm{C}$-labeled isotopolog of citrate, a-ketoglutarate, 
A

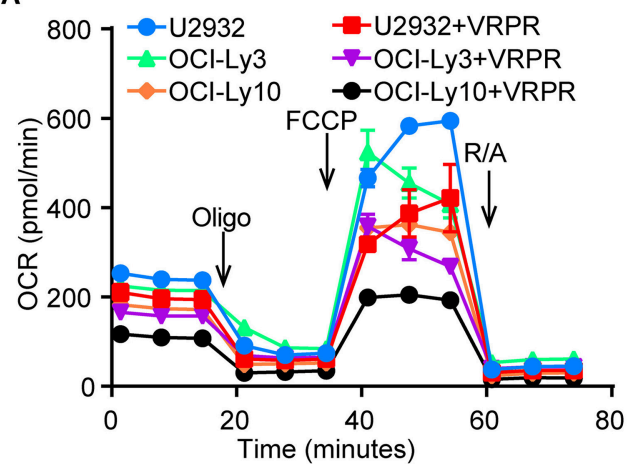

B

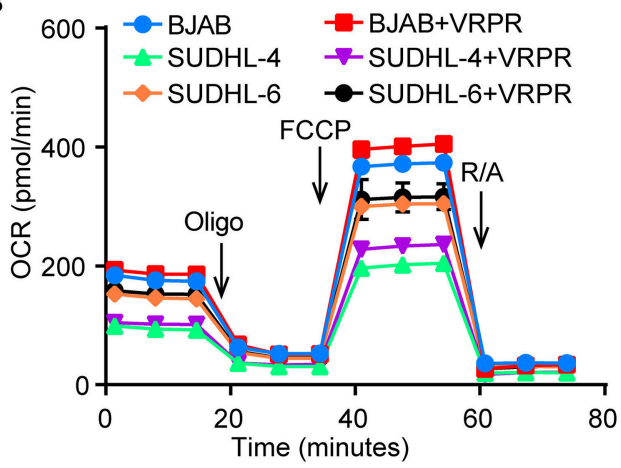

E
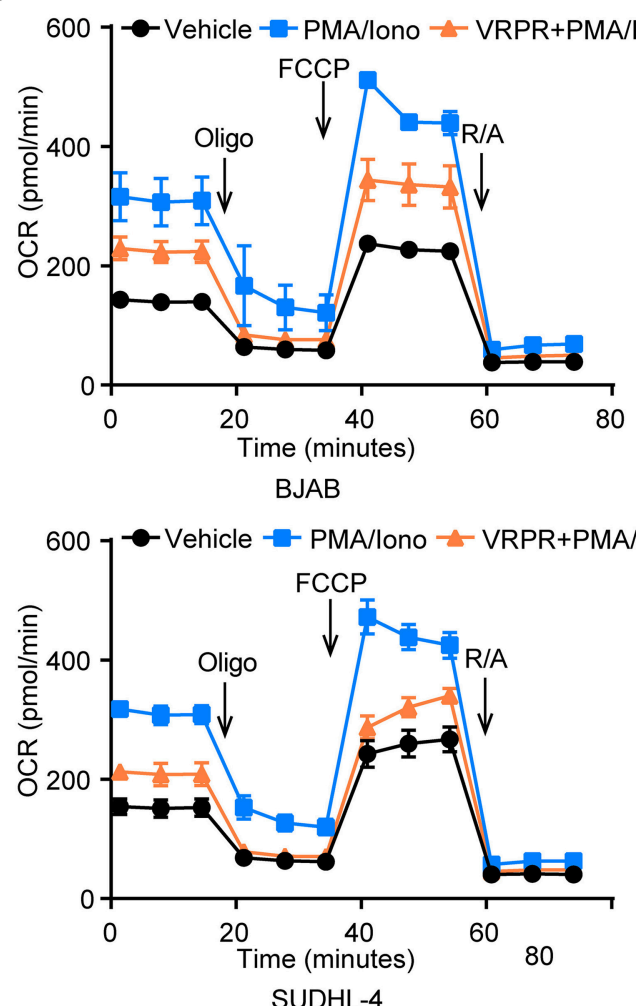

C
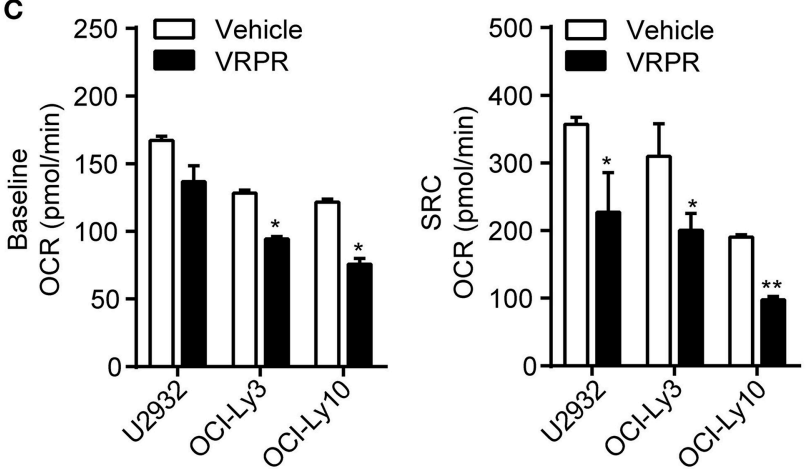

D
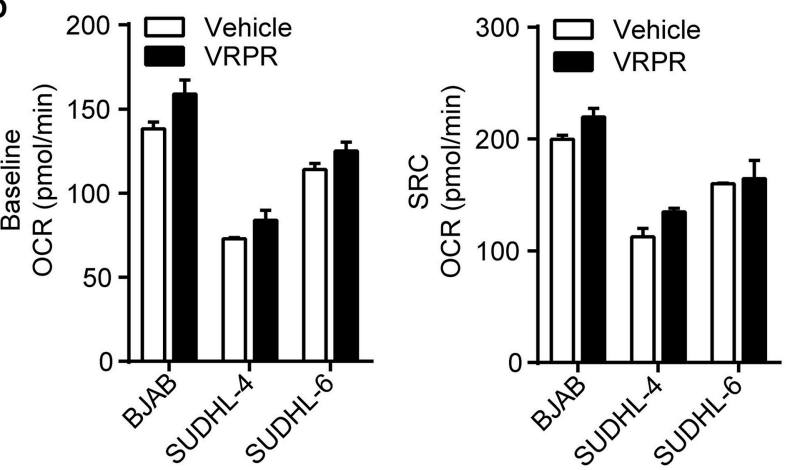

$\mathbf{F}$
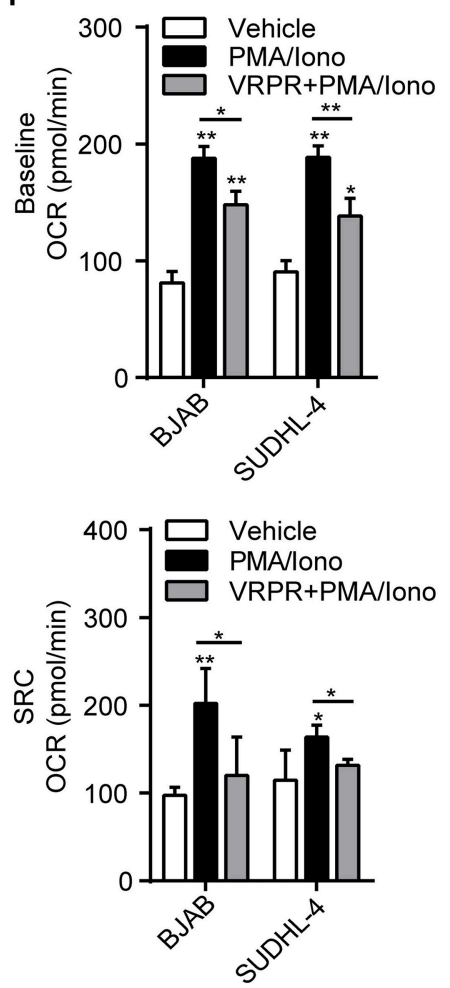

FIGURE 4 | MALT1 protease activity endowed ABC-DLBCL cells with latent mitochondrial bioenergetics ability. Mitochondrial respiration profiles in ABC-DLBCL cells (A) and GCB-DLBCL cells (C) treated with vehicle or VRPR. (B) Baseline OCR and mitochondrial spare respiratory capacity (SRC) of the graphs in (A) were

calculated. (D) Baseline OCR and SRC of the graphs in (C) were calculated. (E) Mitochondrial respiration profiles in GCB-DLBCL cells (BJAB and SUDHL-4 cells) that were either left untreated or stimulated for $12 \mathrm{~h}$ with PMA/lono (P/I); zVRPR-fmk was added $12 \mathrm{~h}$ before stimulation where indicated. (F) Baseline OCR and SRC of the graphs in (E) were calculated. All the graphs represent as the mean \pm SD of three independent experiments. ${ }^{\star} p<0.05 ;{ }^{* *} p<0.01$. 
succinate, fumarate, and malate $(\mathrm{m}+2$ forms, circled green), were increased (Figure 5A). Notably, a large fraction of these TCA metabolites $(\mathrm{m}+0$ forms, circled red) were not derived from the $\left[\mathrm{U}_{-}{ }^{13} \mathrm{C}\right]$-glucose (Figure 5A), suggesting that an alternative source supported mitochondrial bioenergetics via TCA cycling. Meanwhile, these TCA metabolites $(\mathrm{m}+0$ forms, circled red) decreased under MALT1 protease activity inhibition conditions (Figure 5A). These data suggest that glutamate from glutaminolysis likely entered the TCA cycle, which was attenuated by MALT1 protease activity inhibition. Subsequently, we found that the levels of GLS1 protein (Figure 5B) and intracellular glutamate (Figure 5C) were down-regulated in ABC-DLBCL cells without MALT1 protease activity but upregulated in GCB-DLBCL cells with MALT1 protease activity (Supplementary Figures 3B,C). These data indicate that MALT1 protease activity promoted glutaminolysis by enhancing GLS1 expression, producing substantial glutamate that entered the TCA cycle to support mitochondrial bioenergetics. Next, we determined whether enhanced mitochondrial SRC was attributed to glutaminolysis-mediated mitochondrial bioenergetics. We exposed ABC-DLBCL cells to the GLS1 inhibitor BPTES, which blocks glutaminolysis by inhibiting the chemical conversion of glutamine to glutamate (Supplementary Figure 3D). Treatment with either BPTES or z-VRPR-fmk impaired mitochondrial SRC in ABC-DLBCL cells (Figures 5D,E). Administration of BPTES showed no additional decline in mitochondrial SRC when combined with $z$-VRPR-fmk (Figures 5D,E), suggesting that the enhancement effect of MALT1 on mitochondrial SRC was dependent on glutaminolysis in ABC-DLBCL cells. Together, these data established that MALT1 protease activity up-regulated GLS1 expression, thereby promoting glutaminolysis-mediated mitochondrial bioenergetics in ABC-DLBCL cells.

\section{Glutaminolysis Enhanced PD-L1+ ABC-DLBCL Cell Generation to Subvert the Cytotoxicity of Human $\mathrm{V}_{\gamma} 9 \mathrm{~V} \delta 2 \mathrm{~T}$ lymphocytes}

To explore whether glutaminolysis enhanced the generation of PD-L1 ${ }^{+}$ABC-DLBCL cells, we exposed DLBCL cells to BPTES and co-cultured them with $\mathrm{V} \gamma 9 \mathrm{~V} \delta 2 \mathrm{~T}$ lymphocytes. After treatment with BPTES, glutaminolysis was effectively blocked, as indicated by the decreased intracellular glutamate levels (Figure 6A), while survival of these DLBCL cells was not influenced before exposure to $\mathrm{V} \gamma 9 \mathrm{~V} \delta 2 \mathrm{~T}$ lymphocytes (Supplementary Figure 4). Compared with that of GCB-DLBCL cells, $\mathrm{PD}-\mathrm{L1}^{+}$cell generation was significantly depressed (Figure 6B) and ABC-DLBCL cell death was promoted (Figure 6C) by BPTES exposure. BPTES administration did not further improve the cytotoxicity of $\mathrm{V} \gamma 9 \mathrm{~V} \delta 2 \mathrm{~T}$ lymphocytes combined with anti-PD-L1 antibodies (Figures 6D,E), suggesting that the attenuation effect of BPTES on immunesuppressive function was mediated by $\mathrm{PD}-\mathrm{L} 1$ expression in ABC-DLBCL cells. To determine the extent to which the anti-cytotoxicity effects of MALT1 protease activity in ABCDLBCL cells are glutaminolysis-dependent, we pretreated ABC-DLBCL cells with z-VRPR-fmk and BPTES separately or in combination followed by co-culture with $\mathrm{V} \gamma 9 \mathrm{~V} \delta 2 \mathrm{~T}$ lymphocytes. The combination of both inhibitors did not increase the cell death rate compared with the effect of either inhibitor alone (Figure 6F), which suggested that glutaminolysis mediated the immunosuppressive effects of MALT1 protease activity on ABC-DLBCL cells.

\section{Mitochondrial Bioenergetics Mediated by Glutaminolysis Supports STAT3 Activation}

To understand how glutaminolysis promotes $\mathrm{PD}-\mathrm{L}^{+}$ ABC-DLBCL cell generation, we blocked glutaminolysis in ABC-DLBCL cells using BPTES and then co-cultured them with $\mathrm{V} \gamma 9 \mathrm{~V} \delta 2 \mathrm{~T}$ lymphocytes. After sorting DLBCL cells, we measured the changes in total and phosphorylated p65, AKT, ERK, and STAT3 protein levels. As shown in Figure 7A, STAT3 phosphorylation was almost completely inhibited by treatment with BPTES in ABC-DLBCL cells, indicating its activation was inhibited by blocking glutaminolysis. In contrast, p65, AKT and ERK phosphorylation was not impacted, suggesting that STAT3 is the major regulator of PD-L1. Resupplementation of glutamate completely recovered the reduced levels of intracellular glutamate and phospho-STAT3 caused by BPTES treatment (Figures $7 \mathbf{B}, \mathbf{C}$ ), indicating that glutamate or glutamate-mediated mitochondrial bioenergetics plays an important role in maintaining phospho-STAT3. To further confirm that glutamate-mediated mitochondrial bioenergetics maintains phospho-STAT3 or glutamate, we detected the mitochondrial respiration profiles of ABC-DLBCL cells after glutamate re-supplementation in the presence of BPTES. ABC-DLBCL cells showed a lower mitochondrial SRC in the presence of BPTES, which recovered to levels as high as those observed in the original state when glutamate was resupplied, indicating that glutamate entered the TCA cycle to support mitochondrial bioenergetics (Figures 7D,E). Moreover, glutamate re-supplementation did not recover the phosphoSTAT3 levels to those observed in the original state in cells treated with CPI-613, which functions as a TCA cycle blocker (Figure 7F). These data illustrate that glutaminolysis-mediated mitochondrial bioenergetics helped to sustain phospho-STAT3, a PD-L1 transcription factor, which finally led to generation of $\mathrm{PD}-\mathrm{L} 1^{+} \mathrm{ABC}-\mathrm{DLBCL}$ cells under $\mathrm{V} \gamma 9 \mathrm{~V} \delta 2 \mathrm{~T}$ lymphocyte stress.

\section{DISCUSSION}

PD-L1 expression is exploited by various tumor cells, including gastric cancer, hepatocellular carcinoma, renal cell carcinoma, esophageal cancer, pancreatic cancer, and ovarian cancer cells, to subvert T-cell-mediated immunosurveillance (27). Recently, evidences have shown that $\mathrm{PD}-\mathrm{L} 1$ is also predominately expressed in the aggressive $\mathrm{ABC} /$ non-GCB subtype of DLBCL $(13,28)$. However, the molecular mechanism by which PD-L1 expression is regulated in ABC-DLBCL remains unknown. In this study, we report for the first time that MALT1 protease activity coupled to glutaminolysis contributes to $\mathrm{PD}-\mathrm{L} 1$ expression on ABC-DLBCL cells, leading to immunosuppression against $\mathrm{V} \gamma 9 \mathrm{~V} \delta 2 \mathrm{~T}$ lymphocytes. This 

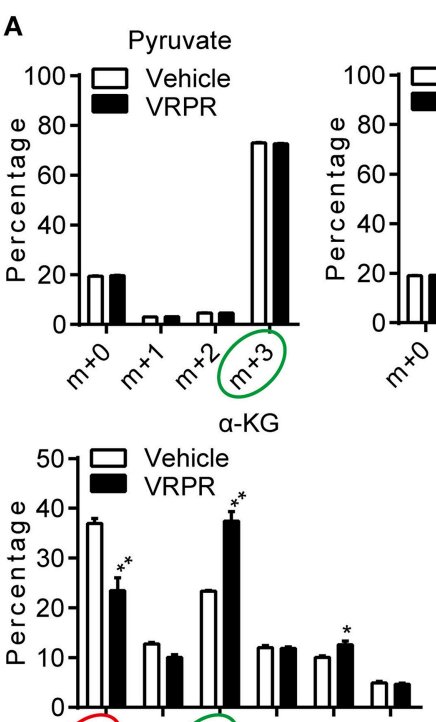

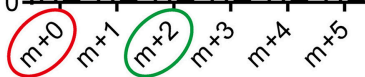

B

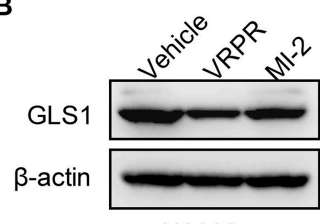

U2932
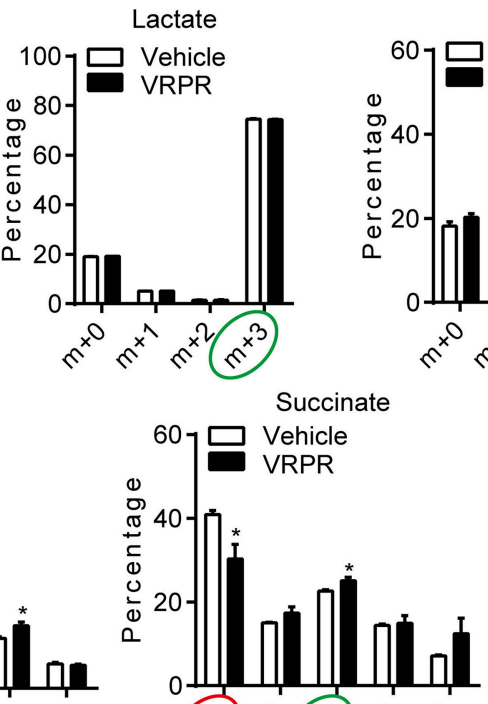

(6) $x^{x^{2}} c^{x^{2}} n^{x^{3}} r^{x^{x}}$

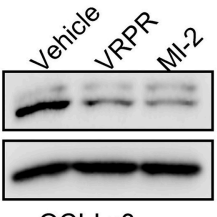

OCl-Ly3

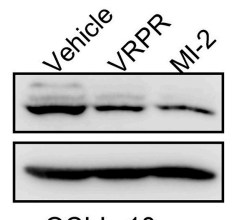

OCl-Ly10

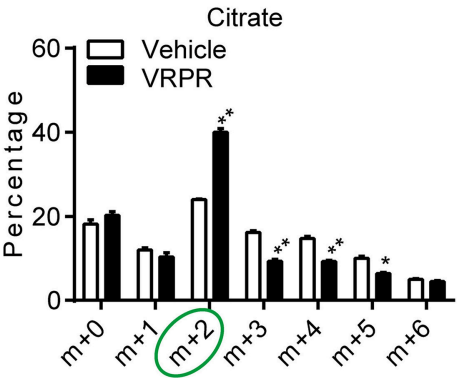

Fumarate

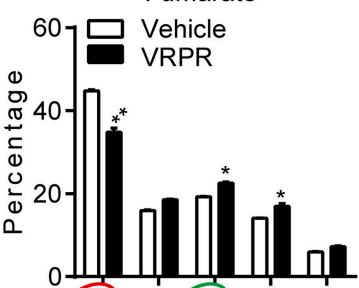

(5) $x^{x}\left(n^{x}\right) n^{x^{3}} n^{x^{x}}$

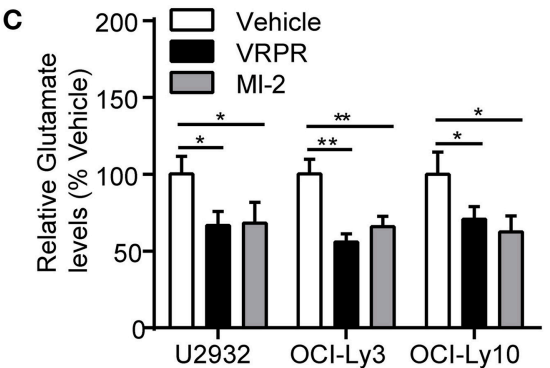

D

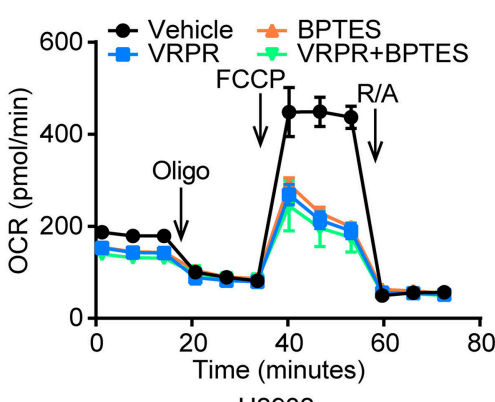

U2932

E

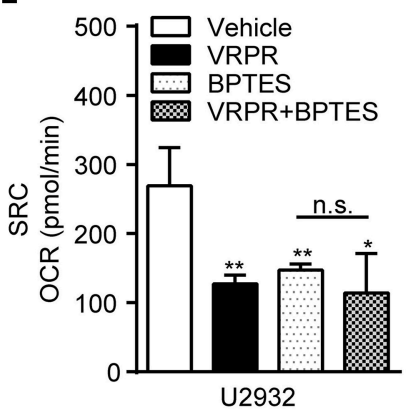

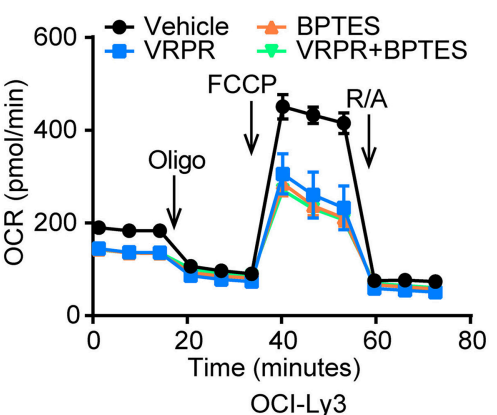
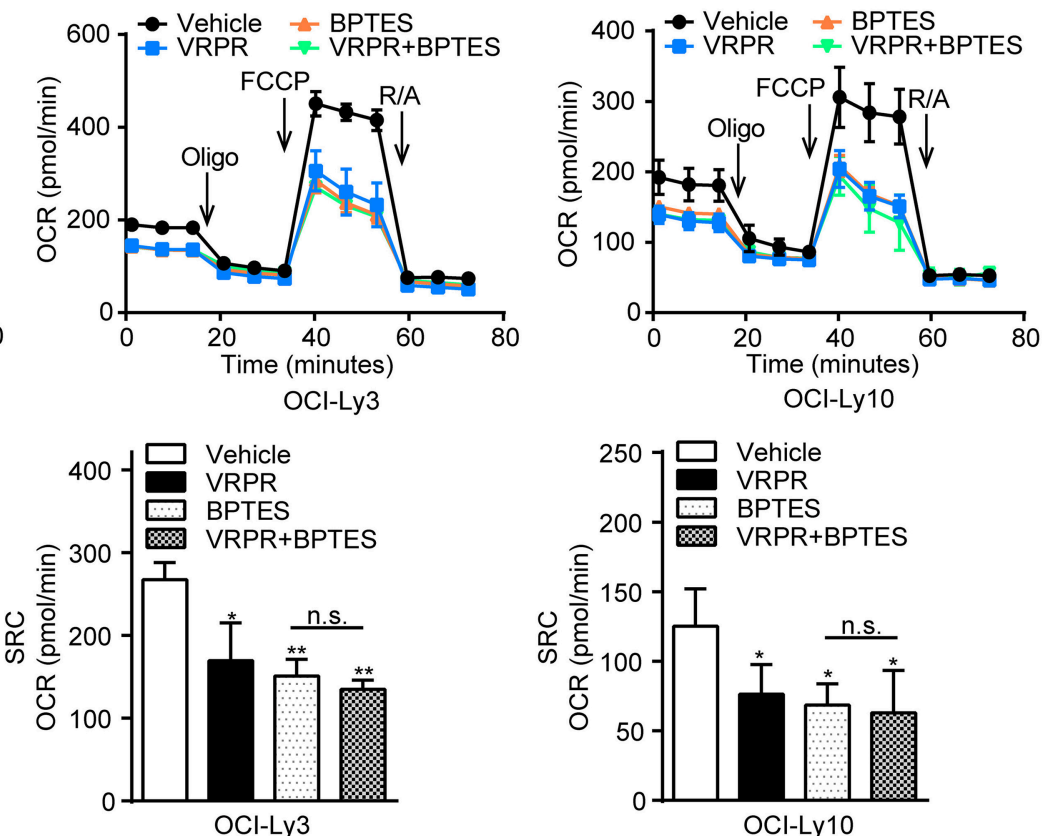

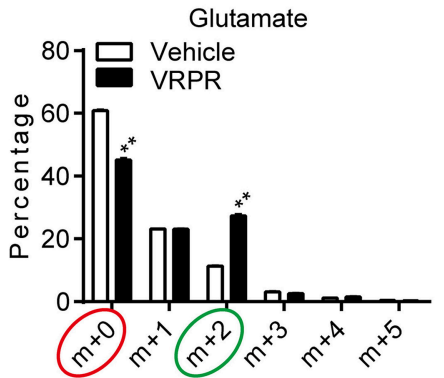

Malate

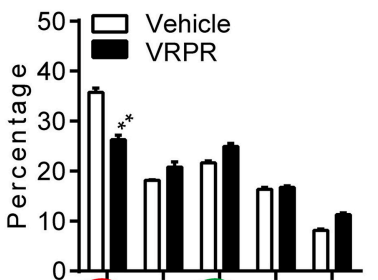

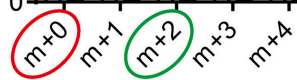

FIGURE 5 | MALT1 protease activity-supported mitochondrial bioenergetics is dependent on glutaminolysis. (A) ${ }^{13} \mathrm{C}$ isotopomer analysis of uniformly labeled glucose $\left(\mathrm{U}^{13} \mathrm{C}_{6}\right.$-glucose) in U2932 cells treated with z-VRPR-fmk or not for $12 \mathrm{~h}$. The isotopolog distributions were determined by GC-MS. The incorporation of ${ }^{13} \mathrm{C}$ atoms from ${ }^{13} \mathrm{C}_{6}$-Glc into pyruvate, lactate, citrate, a-ketoglutarate $(a-K G)$, succinate, fumarate, and malate are denoted as $m+n$, where $n$ is the number of ${ }^{13} \mathrm{C}$ atoms. (B) Western blot to detect GLS1 in ABC-DLBCL cells pretreated with vehicle, VRPR or MI-2 for $12 \mathrm{~h}$. $\beta$-Actin blotting served as the loading control. One representative

(Continued) 
FIGURE 5 | experiment of three is depicted. (C) Relative glutamate levels in ABC-DLBCL cells from (B). (D) Profiles of mitochondrial respiration in ABC-DLBCL cells pretreated with vehicle, VRPR, BPTES, or VRPR+BPTES for $12 \mathrm{~h}$. OCR was assayed after consecutive injections of Oligo ( $1 \mu \mathrm{M})$, FCCP $(0.5 \mu \mathrm{M})$, rotenone ( $1 \mu \mathrm{M})$, and antimycin $(1 \mu \mathrm{M})$. (E) OCR of the graphs in (D) were calculated. All the graphs represent as the mean \pm SD of three independent experiments. ${ }^{\star} p<0.05 ;{ }^{\star \star} p<0.01$.
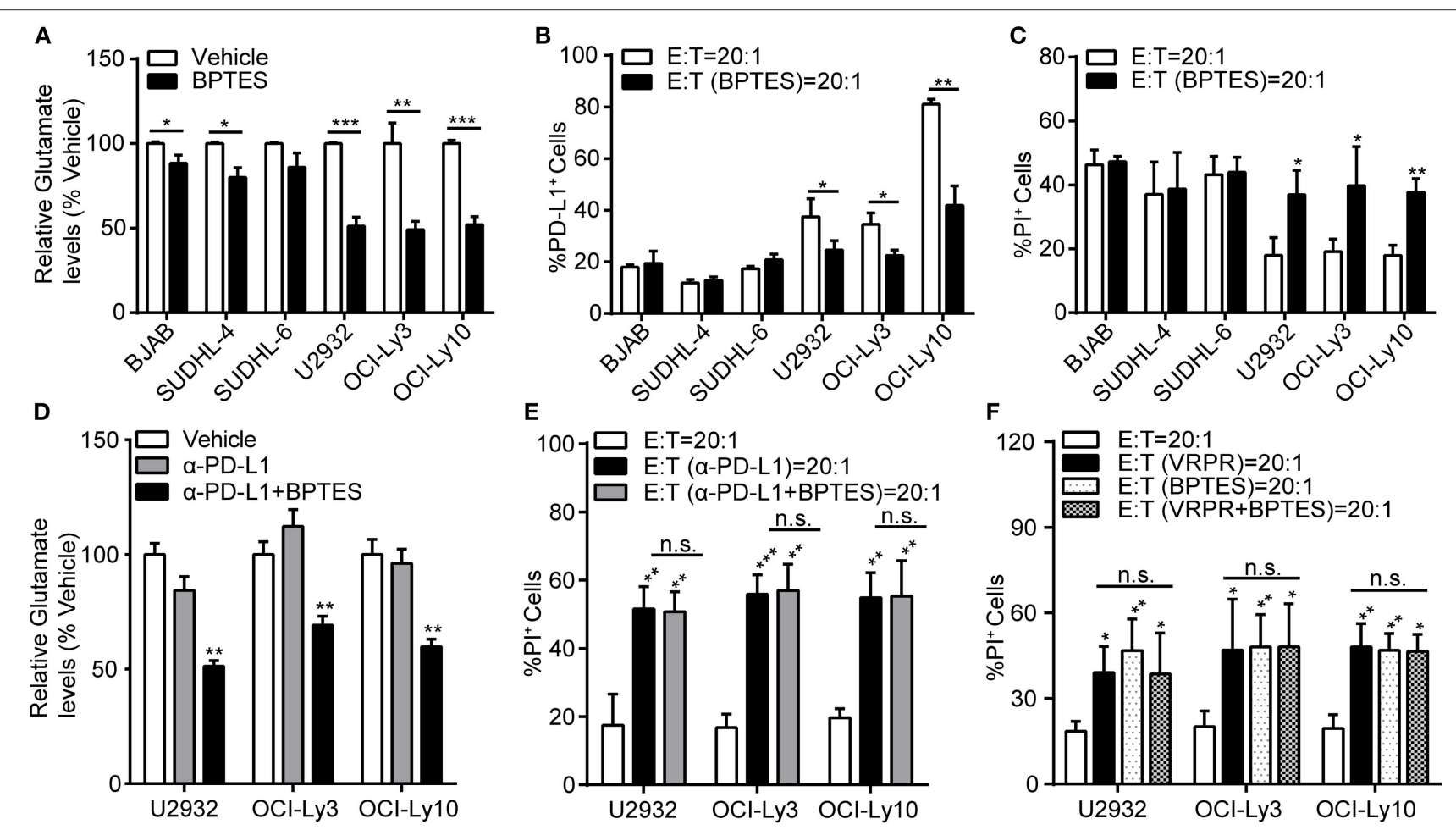

FIGURE 6 | Glutaminolysis enhanced PD-L1+ ABC-DLBCL cell generation to subvert the cytotoxicity of human $\mathrm{V} \gamma 9 \mathrm{~V} \delta 2 \mathrm{~T}$ lymphocytes. (A) Relative glutamate levels in DLBCL cells pretreated with vehicle or BPTES for $12 \mathrm{~h}$. (B) DLBCL cells were pretreated with vehicle or BPTES for $12 \mathrm{~h}$ before being exposed to CFSE-labeled V $\gamma 9 \mathrm{~V} \delta 2 \mathrm{~T}$ lymphocytes for $6 \mathrm{~h}$. Proportions of PD-L1+ DLBCL cells were detected $(n=5)$. (C) Cytotoxicity of V $\gamma 9 \mathrm{~V} \delta 2 \mathrm{~T}$ lymphocytes toward DLBCL cells from (B) $(n=5)$. (D) Relative glutamate levels in DLBCL cells pretreated with vehicle, anti-PD-L1 antibody, or anti-PD-L1 antibody + BPTES ( $\alpha-P D-L 1+B)$ for 12 h. (E) Cytotoxicity of $\mathrm{V} \gamma 9 \mathrm{~V} \delta 2 \mathrm{~T}$ lymphocytes toward ABC-DLBCL cells from (D) $(n=5)$. (F) Cytotoxicity of $\mathrm{V} \gamma 9 \mathrm{~V} \delta 2 \mathrm{~T}$ lymphocytes toward ABC-DLBCL cells pretreated with vehicle, $z$-VRPR-fmk, BPTES, or $z$-VRPR-fmk + BPTES for $12 \mathrm{~h}(n=5)$. Data are shown as the means $\pm \mathrm{SD}$, ${ }^{*} p<0.05 ;{ }^{* \star} p<0.01$; ${ }^{\star \star *} p<0.001$.

study reveals a novel mechanism of PD-L1 regulation and indicates that glutaminolysis restriction may support novel immunotherapy approaches for ABC-DLBCL.

$\mathrm{V} \gamma 9 \mathrm{~V} \delta 2 \mathrm{~T}$ lymphocytes are involved in tumor-immune surveillance, notably against carcinomas and hematologic malignancies (29). In contrast with $\alpha \beta$ T lymphocytes, V $\gamma 9 \mathrm{~V} \delta 2 \mathrm{~T}$ lymphocytes mediate potent antitumor effects in a HLAunrestricted manner (30). In addition, they can be expanded routinely in vitro. More importantly, the expression of the ligand PD-L1 on tumor cells hampers the functional antitumor response of $\mathrm{V} \gamma 9 \mathrm{~V} \delta 2 \mathrm{~T}$ lymphocytes (31). These factors suggest that $\mathrm{V} \gamma 9 \mathrm{~V} \delta 2 \mathrm{~T}$ lymphocytes are a convenient and reasonable choice for studying immune evasion mediated by the PD-1/PDL1 axis in vitro. GCB-DLBCL and ABC-DLBCL show distinct PD-L1 expression, and thus, first, we examined the immune evasion ability of ABC-DLBCL and GCB-DLBCL cells against V $\gamma 9 \mathrm{~V} \delta 2 \mathrm{~T}$ lymphocytes. We observed that ABC-DLBCL cells were more inclined to subvert the cytotoxicity of $\mathrm{V} \gamma 9 \mathrm{~V} \delta 2 \mathrm{~T}$ lymphocytes than GCB-DLBCL cells. However, this immune evasion ability was significantly attenuated by inhibition of MALT1 protease activity. The proportion of $\mathrm{PD}-\mathrm{L1}^{+} \mathrm{ABC}-$ DLBCL cells was obviously reduced under $\mathrm{V} \gamma 9 \mathrm{~V} \delta 2 \mathrm{~T}$ lymphocyte stress prior to inactivation of MALT1 protease activity, while that of $\mathrm{PD}-\mathrm{L1}^{+} \mathrm{GBC}-\mathrm{DLBCL}$ cells was much less reduced. In addition, $\mathrm{PD}-\mathrm{Ll}$ blockage reduced the immune evasion function of ABC-DLBCL cells, but no further attenuation was seen by inhibiting MALT1 protease activity. These data revealed that PDL1 expression on ABC-DLBCL cells causes immune evasion that is mediated by MALT1 protease activity. More interestingly, we noticed that the DLBCL cell lines used in our study are PD-L1 negative, except for the OCI-Ly10 cell line. Only when exposed to $\mathrm{V} \gamma 9 \mathrm{~V} \delta 2 \mathrm{~T}$ lymphocytes did these DLBCL cells express PDL1. PD-L1 up-regulation on tumor cells might be a consequence of pro-inflammatory cytokines produced by tumor infiltrating immune cells. For example, IFN- $\gamma$ produced by inflammatory cells acts as a potent PD-L1 up-regulator (15). Another study noted that PD-L1 expressed on tumor cells is immunologically active in suppressing tumor-associated $\mathrm{T}$ cell activation (9). 

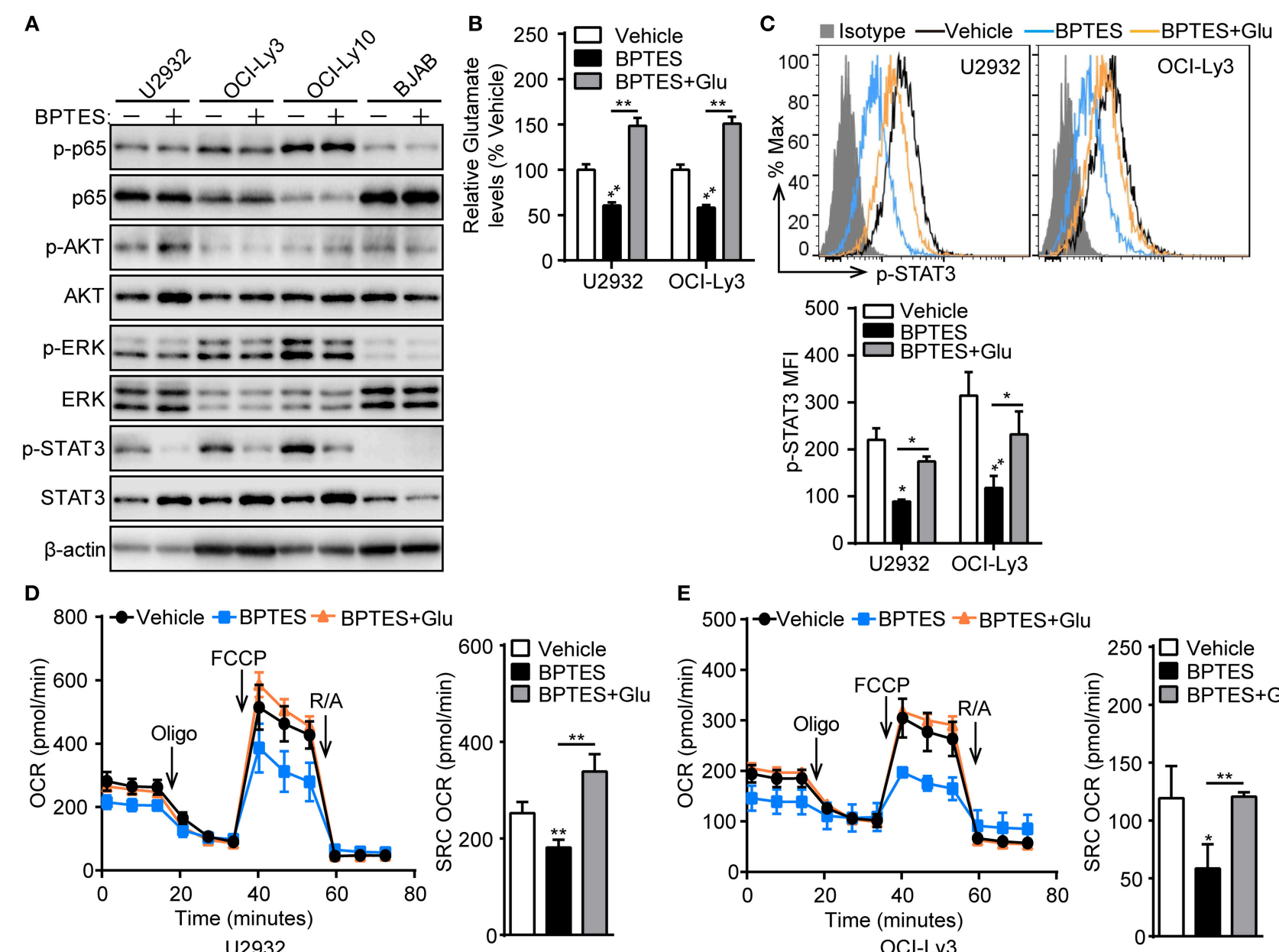

$\mathbf{E}$
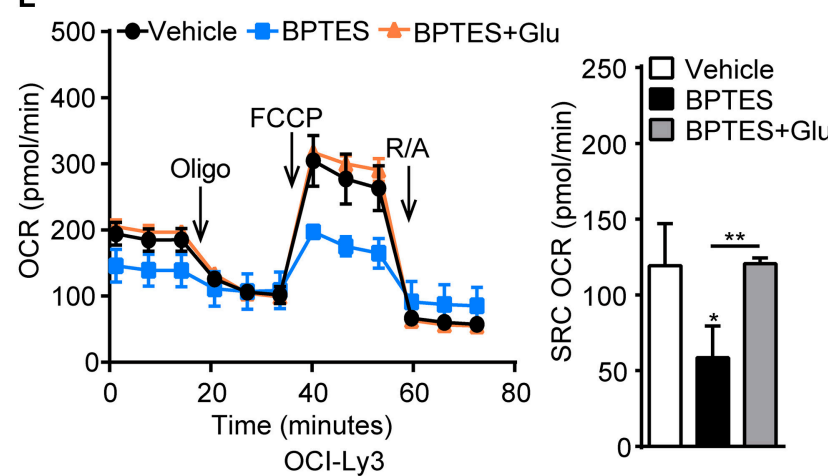

$\mathbf{F}$
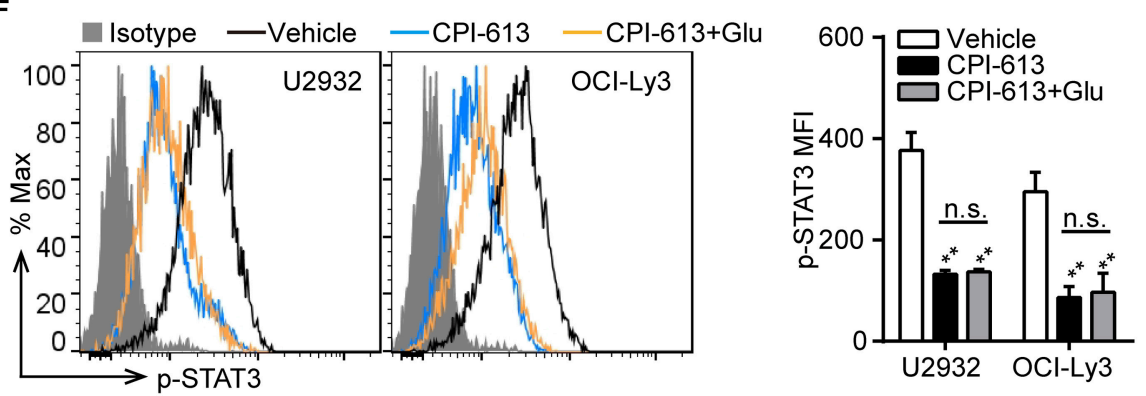

FIGURE 7 | Mitochondrial bioenergetics mediated by glutaminolysis supports STAT3 activation. (A) ABC-DLBCL cells and BJAB cells were treated with BPTES (+) or not (-) for $12 \mathrm{~h}$ before being exposed to CFSE-labeled $\mathrm{V} \gamma 9 \mathrm{~V} \delta 2 \mathrm{~T}$ lymphocytes for $6 \mathrm{~h}$. Western blot to detect changes in the indicated proteins in sorted DLBCL cells. (B) Relative glutamate levels of U2932 and OCl-Ly3 cells treated with vehicle, BPTES or BPTES + Glutamate (Glu) for $12 \mathrm{~h}$. One representative experiment of three is depicted. (C) U2932 and OCI-Ly3 cells from (B) were exposed to CFSE-labeled V $\gamma 9 \mathrm{~V} \delta 2 \mathrm{~T}$ lymphocytes for $6 \mathrm{~h}$. Changes of p-STAT3 levels were detected in sorted U2932 and OCI-Ly3 cells by flow cytometry, and the MFI of p-STAT3 was calculated ( $n=3$ ). Mitochondrial respiration profiles in U2932 (D) and OCI-Ly3 cells (E) from (B) $(n=3)$. (F) U2932 and OCI-Ly3 cells were treated with vehicle, CPI-613 or CPI-613+Glutamate (Glu) for $12 \mathrm{~h}$ prior to exposure to CFSE-labeled V $\gamma 9 \mathrm{~V} \delta 2 \mathrm{~T}$ lymphocytes for $6 \mathrm{~h}$. Changes of p-STAT3 levels were detected in sorted U2932 and OCI-Ly3 cells by flow cytometry, and the MFI of p-STAT3 was calculated ( $n=3$ ). Data are shown as the means $\pm S D,{ }^{*} p<0.05 ;{ }^{* *} p<0.01$.

Accordingly, the emergence of PD-L1 ${ }^{+}$DLBCL cells was likely induced by certain pro-inflammatory cytokines secreted by $\mathrm{V} \gamma 9 \mathrm{~V} \delta 2 \mathrm{~T}$ lymphocytes in our experimental system. Overall, we found that MALT1 protease activity is essential for $\mathrm{PD}-\mathrm{L1}^{+} \mathrm{ABC}-$ DLBCL generation under the immune pressure of $\mathrm{V} \gamma 9 \mathrm{~V} \delta 2 \mathrm{~T}$ lymphocytes. 
Furthermore, we detected the scale of $\mathrm{PD}-1^{+} \mathrm{V} \gamma 9 \mathrm{~V} \delta 2 \mathrm{~T}$ lymphocyte generation, which accounted for an average of $~ 20 \%$ of the lymphocytes on day 13 during in vitro culture. Our observations of the pattern of PD-1 expression by $\mathrm{V} \gamma 9 \mathrm{~V} \delta 2 \mathrm{~T}$ lymphocytes are consistent with those of other reports (32). Following antigenic stimulation, $\mathrm{V} \gamma 9 \mathrm{~V} \delta 2 \mathrm{~T}$ lymphocytes express high levels of PD-1 $(29,32,33)$. Consequently, the proportion of $\mathrm{PD}-1^{+} \mathrm{V} \gamma 9 \mathrm{~V} \delta 2 \mathrm{~T}$ lymphocytes significantly increased in the presence of $\mathrm{ABC}-\mathrm{DLBCL}$ cells regardless of whether they were pretreated with or without $\mathrm{z}$-VRPR-fmk. Apart from that, cytokines, including IL-2, IL-6, IL-7, IL-15, IL-21, IFN- $\alpha$, and TNF- $\alpha$, are also thought to induce PD-1 expression in activated T lymphocytes $(34,35)$. ABC-DLBCL cells ordinarily produce some of these cytokines $(36,37)$, which might be another reason for the increased generation of PD-1 ${ }^{+} \mathrm{V} \gamma 9 \mathrm{~V} \delta 2 \mathrm{~T}$ lymphocytes. Persuasively, we found that IL-6 mRNA levels were identical in ABC-DLBCL cells pretreated with either z-VRPR-fmk or vehicle, and these levels increased after exposure to $\mathrm{V} \gamma 9 \mathrm{~V} \delta 2 \mathrm{~T}$ lymphocytes. This hints that IL- 6 may be one of the inducers of PD-1 expression on V $\gamma 9 \mathrm{~V} \delta 2 \mathrm{~T}$ lymphocytes in our experimental system. Altogether, inducible $\mathrm{PD}-\mathrm{L} 1$ and $\mathrm{PD}-1$ provide favorable conditions for ABC-DLBCL cells to exert immune-suppressive activity. Inhibition of MALT1 protease activity potentially provides an approach for reversing increases in the proportion of PD-L1 ${ }^{+}$ABC-DLBCL cells, thereby weakening their immuneevasion property, although it does not influence the $\mathrm{PD}-1^{+}$ V $\gamma 9$ V $82 \mathrm{~T}$ lymphocyte number. Therefore, MALT1 protease activity inhibition depressed the immunosuppressive property of ABC-DLBCL cells by attenuating the probability of PD-L1/PD-1 interaction.

MALT1 protease activity plays an essential role in activation of NF- $\kappa \mathrm{B}$, which functions as a transcription factor of PDL1 in tumor cells (24). We originally speculated that NF- $\kappa B$ is indispensable for the ability of MALT1 protease activity to mediate $\mathrm{PD}-\mathrm{L}^{+}{ }^{+} \mathrm{ABC}-\mathrm{DLBCL}$ cell generation. Unexpectedly, in the absence of NF- $\kappa \mathrm{B}$ transcription activity, the proportion of $\mathrm{PD}-\mathrm{L} 1^{+} \mathrm{ABC}-\mathrm{DLBCL}$ cells was obviously decreased via MALT1 protease activity inhibition under $\mathrm{V} \gamma 9 \mathrm{~V} \delta 2 \mathrm{~T}$ lymphocyte stress. This suggested that another pathway, parallel to NF- $\kappa$ B and supporting PD-L1 expression, might be destroyed by MALT1 protease activity inhibition. The lack of NF- $\mathrm{B}$ transcription activity reduction might be caused by activation of the signaling adaptor MYD88, which is another prominent NF-кB signaling pathway activator in ABC-DLBCL cells $(38,39)$. In addition, direct blockade of NF- $\kappa \mathrm{B}$ transcription activity by QNZ slightly inhibited the generation of $\mathrm{PD}-\mathrm{L1}^{+} \mathrm{ABC}-\mathrm{DLBCL}$ cells in response to $\mathrm{V} \gamma 9 \mathrm{~V} \delta 2 \mathrm{~T}$ lymphocytes, which further indicated that NF- $\kappa \mathrm{B}$ is dispensable for the PD-L1 ${ }^{+} \mathrm{ABC}-\mathrm{DLBCL}$ cell generation mediated by MALT1 protease activity.

Recent studies have shown a possible link between metabolic alteration and PD-L1 expression $(18,19)$. Accordingly, we proposed that MALT1 protease activity might regulate cell metabolic reprogramming to support $\mathrm{PD}-\mathrm{L}^{+}{ }^{+} \mathrm{ABC}-\mathrm{DLBCL}$ cell generation. Following this assumption, we observed that MALT1 protease activity inhibition led to low levels of mitochondrial SRC in ABC-DLBCL cells. Mitochondrial SRC has a positive correlation with mitochondrial bioenergetics, which is supported by loading of pyruvate or glutamate into mitochondria (40, $41)$. In our study, glutamate $(m+0)$ derived from glutamine significantly decreased while glucose-derived pyruvate $(m+3)$ and lactate $(\mathrm{m}+3)$ were not influenced by MALT1 protease activity inhibition. This suggested that glutaminolysis might be the target of MALT1 protease activity. Furthermore, importantly, many metabolites $(\mathrm{m}+0)$ of the TCA cycle are derived from glutaminolysis. The levels of these metabolites were reduced by MALT1 protease activity inhibition, which was the reason for the increased percentage of glucose-derived metabolites $(\mathrm{m}+2)$ in the TCA cycle. Critically, these new observations may help us better understand the metabolic characteristics of ABC-DLBCL cells and provide a basis for developing therapeutic approaches aimed at modulating cell proliferation and apoptosis (42). Because of the function of MALT1 protease activity in glutamate production, we observed that MALT1 protease activity positively regulated GLS1 expression. Therefore, MALT1 protease activity endows ABC-DLBCL cells with high mitochondrial bioenergetics ability, which is mediated by glutaminolysis.

Subsequently, our data show that glutamate derived from glutaminolysis supports mitochondrial bioenergetics and enhances PD-L1 expression in ABC-DLBCL cells in response to V $\gamma 9 \mathrm{~V} \delta 2 \mathrm{~T}$ lymphocytes. This is distinct from CAD macrophages, in which PD-L1 expression is mechanistically linked to pyruvate-mediated mitochondrial bioenergetics (19). PD-L1 is modulated by the PI3K/AKT and MAPK pathways or several transcription factors, including HIF-1, NF- $\kappa$, and STAT3 (14-17). Among these factors, STAT3 is the only essential mediator that was inhibited by glutaminolysis blockade under V $\gamma 9$ V $82 \mathrm{~T}$ lymphocyte stress. This suggested that glutamate derived from glutaminolysis plays an essential role in STAT3 activation. At least two possibilities can explain how glutamate activates STAT3. First, glutamate itself may directly activate STAT3 without metabolic processing (43). However, our data argue against this possibility because addition of glutamate did not promote STAT3 activation under TCA cycle blockade. Therefore, the second possibility is more likely: glutamate acted as an intracellular metabolite that entered the TCA cycle for mitochondrial bioenergetics, thereby supporting STAT3 activation. In addition, replacement of glutamate recovered mitochondrial SRC, which further supports this hypothesis.

Glutaminolysis is thought to be the main source of energy production in tumor cells, which show elevated levels of enzymes involved in glutamine/glutamate oxidation compared with those in normal cells (44). This metabolic abnormality maintains a functional TCA cycle for respiration and compensates for increased demands of biosynthetic precursors. In addition, glutaminolysis also plays an important role in regulating redox balance, apoptosis and autophagy in cancer cells. Here, we discovered a novel biological function of glutaminolysis that involves immune evasion, indicating that blocking glutaminolysis might benefit immunotherapy for ABCDLBCL. GLS is the initial enzyme in glutaminolysis and catalyzes the conversion of glutamine to glutamate, and it is the most extensively studied drug target in the glutaminolysis pathway. In our study, GLS inhibition decreased PD-L1 expression under immune pressure, which attenuated the immunosuppressive 
property of tumor cells. This suggests that GLS inhibition has the dual functions of inhibiting tumor cell growth and immune evasion. Therefore, characterizing new specific inhibitors for GLS should become a field of intense research.

In summary, as shown in Graphical Abstract, our findings provide evidence that MALT1 protease activity, known to play an important role in NF- $\kappa \mathrm{B}$ activation and pathogenesis of ABC-DLBCL, promotes glutaminolysis by up-regulating GLS1 expression and facilitates the generation of $\mathrm{PD}-\mathrm{L}^{+}$ ABC-DLBCL cells. The glutaminolysis intermediate glutamate enhances mitochondrial bioenergetics, resulting in STAT3 activation and PD-L1 expression. This endows ABC-DLBCL cells with an immunosuppressive property. Our study provides a new perspective to deepen our understanding of $\mathrm{PD}$ $\mathrm{L1}^{+} \mathrm{ABC}-\mathrm{DLBCL}$ cell generation under immune pressure. Hence, manipulation of these pathways could hold enormous potential for the development of effective immunotherapy for ABC-DLBCL.

\section{AUTHOR CONTRIBUTIONS}

$\mathrm{XX}$ and WZ wrote the manuscript, made the figures, and performed research. CG wrote the manuscript. ZF, PL, YX, $\mathrm{LiZ}$, and $\mathrm{HZ}$ assisted with the experiments. LeZ revised the manuscript. XX and CS discussed and interpreted the data. YG directed the project, secured funding, and refined the manuscript.

\section{REFERENCES}

1. Slater DN. The new World Health Organization classification of haematopoietic and lymphoid tumours: a dermatopathological perspective. Br J Dermatol. (2002) 147:633-9. doi: 10.1046/j.1365-2133.2002.05050.x

2. Lenz G, Wright GW, Emre NC, Kohlhammer H, Dave SS, Davis RE, et al. Molecular subtypes of diffuse large B-cell lymphoma arise by distinct genetic pathways. Proc Natl Acad Sci USA. (2008) 105:13520-5. doi: 10.1073/pnas.0804295105

3. Lenz G, Wright G, Dave SS, Xiao W, Powell J, Zhao H, et al. Stromal gene signatures in large-B-cell lymphomas. N Engl J Med. (2008) 359:2313-23. doi: 10.1056/NEJMoa0802885

4. Cunningham D, Hawkes EA, Jack A, Qian W, Smith P, Mouncey P, et al. Rituximab plus cyclophosphamide, doxorubicin, vincristine, and prednisolone in patients with newly diagnosed diffuse large B-cell non-Hodgkin lymphoma: a phase 3 comparison of dose intensification with 14-day versus 21-day cycles. Lancet (2013) 381:1817-26. doi: 10.1016/S0140-6736(13)60313-X

5. Tao L, Clarke CA, Rosenberg AS, Advani RH, Jonas BA, Flowers $\mathrm{CR}$, et al. Subsequent primary malignancies after diffuse large B-cell lymphoma in the modern treatment era. Br J Haematol. (2017) 178:72-80. doi: 10.1111/bjh.14638

6. Karube K, Enjuanes A, Dlouhy I, Jares P, Martin-Garcia D, Nadeu F, et al. Integrating genomic alterations in diffuse large B-cell lymphoma identifies new relevant pathways and potential therapeutic targets. Leukemia (2018) 32:675-84. doi: 10.1038/leu.2017.251

7. Baldwin AS. Control of oncogenesis and cancer therapy resistance by the transcription factor NF-kappaB. J Clin Invest. (2001) 107:241-6. doi: 10.1172/JCI11991

8. Chen J, Jiang CC, Jin L, Zhang XD. Regulation of PD-L1: a novel role of pro-survival signalling in cancer. Ann Oncol. (2016) 27:409-16. doi: 10.1093/annonc/mdv615

\section{FUNDING}

This work was supported by the National Natural Science Foundation of China (grant 31470872 to YG), Guangzhou Science Technology and Innovation Commission (grant 201604020162 to $\mathrm{YG}$ ) and the 111 Project (grant B16021 to YG). This work was also supported by The Program from the Science and Technology Department of Guangdong Province of China (Grant 2017A030313890) and the Science and Technology Program of Guangzhou (Grant 201807010003).

\section{ACKNOWLEDGMENTS}

We thank our donors for participating and donating samples to make this research possible. We also thank Prof. Liang Chen (Institute of Life and Health Engineering, College of Life Science and Technology, Jinan University, Guangzhou, China), Prof. Xiuli Bi (School of Life Science, Liaoning University, Shenyang, China), and Dr. Guangchao Cao (Biomedical Translational Research Institute, Jinan University, Guangzhou, China) for scientific editing of the manuscript.

\section{SUPPLEMENTARY MATERIAL}

The Supplementary Material for this article can be found online at: https://www.frontiersin.org/articles/10.3389/fonc. 2018.00632/full\#supplementary-material

9. Andorsky DJ, Yamada RE, Said J, Pinkus GS, Betting DJ, Timmerman JM. Programmed death ligand 1 is expressed by non-hodgkin lymphomas and inhibits the activity of tumor-associated T cells. Clin Cancer Res.(2011) 17:4232-44. doi: 10.1158/1078-0432.CCR-10-2660

10. Kiyasu J, Miyoshi H, Hirata A, Arakawa F, Ichikawa A, Niino D, et al. Expression of programmed cell death ligand 1 is associated with poor overall survival in patients with diffuse large B-cell lymphoma. Blood (2015) 126:2193-201. doi: 10.1182/blood-2015-02-629600

11. Quan L, Chen X, Liu A, Zhang Y, Guo X, Yan S, et al. PD-1 blockade can restore functions of T-cells in epstein-barr virus-positive diffuse large B-cell lymphoma in vitro. PLoS ONE (2015) 10:e0136476. doi: 10.1371/journal.pone.0136476

12. Burr ML, Sparbier CE, Chan YC, Williamson JC, Woods K, Beavis PA, et al. CMTM6 maintains the expression of PD-L1 and regulates anti-tumour immunity. Nature (2017) 549:101-5. doi: 10.1038/nature23643

13. Georgiou K, Chen L, Berglund M, Ren W, de Miranda NF, Lisboa $\mathrm{S}$, et al. Genetic basis of PD-L1 overexpression in diffuse large Bcell lymphomas. Blood (2016) 127:3026-34. doi: 10.1182/blood-2015-12686550

14. Atefi M, Avramis E, Lassen A, Wong DJ, Robert L, Foulad D, et al. Effects of MAPK and PI3K pathways on PD-L1 expression in melanoma. Clin Cancer Res. (2014) 20:3446-57. doi: 10.1158/1078-0432.CCR-13-2797

15. Lee SJ, Jang BC, Lee SW, Yang YI, Suh SI, Park YM, et al. Interferon regulatory factor-1 is prerequisite to the constitutive expression and IFNgamma-induced upregulation of B7-H1 (CD274). FEBS Lett. (2006) 580:75562. doi: 10.1016/j.febslet.2005.12.093

16. Noman MZ, Desantis G, Janji B, Hasmim M, Karray S, Dessen P, et al. PDL1 is a novel direct target of HIF-1alpha, and its blockade under hypoxia enhanced MDSC-mediated T cell activation. J Exp Med. (2014) 211:781-90. doi: $10.1084 /$ jem.20131916

17. Yao S, Jiang L, Moser EK, Jewett LB, Wright J, Du J, et al. Control of pathogenic effector T-cell activities in situ by PD-L1 expression on respiratory 
inflammatory dendritic cells during respiratory syncytial virus infection. Mucosal Immunol. (2015) 8:746-59. doi: 10.1038/mi.2014.106

18. Wangpaichitr M, Kandemir H, Li YY, Wu C, Nguyen D, Feun LG, et al. Relationship of metabolic alterations and PD-L1 expression in cisplatin resistant lung cancer. Cell Dev Biol. (2017) 6:183. doi: 10.4172/2168-9296.1000183

19. Watanabe R, Shirai T, Namkoong H, Zhang H, Berry GJ, Wallis BB, et al. Pyruvate controls the checkpoint inhibitor PD-L1 and suppresses T cell immunity. J Clin Invest. (2017) 127:2725-38. doi: 10.1172/JCI92167

20. Hailfinger S, Pelzer C, Thome M. Detection and measurement of paracaspase MALT1 activity. Methods Mol Biol. (2014) 1133:177-88. doi: 10.1007/978-1-4939-0357-3_11

21. Hachmann J, Salvesen GS. The Paracaspase MALT1. Biochimie (2016) 122:324-38. doi: 10.1016/j.biochi.2015.09.018

22. Ferch U, Kloo B, Gewies A, Pfander V, Duwel M, Peschel C, et al. Inhibition of MALT1 protease activity is selectively toxic for activated B celllike diffuse large B cell lymphoma cells. J Exp Med. (2009) 206:2313-20. doi: $10.1084 /$ jem. 20091167

23. Fontan L, Yang C, Kabaleeswaran V, Volpon L, Osborne MJ, Beltran E, et al. MALT1 small molecule inhibitors specifically suppress ABC-DLBCL in vitro and in vivo. Cancer Cell (2012) 22:812-24. doi: 10.1016/j.ccr.2012.11.003

24. Peng J, Hamanishi J, Matsumura N, Abiko K, Murat K, Baba T, et al. Chemotherapy induces programmed cell death-ligand 1 overexpression via the nuclear factor-kappaB to foster an immunosuppressive tumor microenvironment in ovarian cancer. Cancer Res. (2015) 75:5034-45. doi: 10.1158/0008-5472.CAN-14-3098

25. Shi L, Chen S, Yang L, Li Y. The role of PD-1 and PD-L1 in T-cell immune suppression in patients with hematological malignancies. J Hematol Oncol. (2013) 6:74. doi: 10.1186/1756-8722-6-74

26. Gowrishankar K, Gunatilake D, Gallagher SJ, Tiffen J, Rizos H, Hersey P. Inducible but not constitutive expression of PD-L1 in human melanoma cells is dependent on activation of NF-kappaB. PLoS ONE (2015) 10:e0123410. doi: 10.1371/journal.pone.0123410

27. Wang X, Teng F, Kong L, Yu J. PD-L1 expression in human cancers and its association with clinical outcomes. Onco Targets Ther. (2016) 9:5023-39. doi: 10.2147/OTT.S105862

28. Chen BJ, Chapuy B, Ouyang J, Sun HH, Roemer MG, Xu ML, et al. PDL1 expression is characteristic of a subset of aggressive B-cell lymphomas and virus-associated malignancies. Clin Cancer Res. (2013) 19:3462-73. doi: 10.1158/1078-0432.CCR-13-0855

29. Gertner-Dardenne J, Fauriat C, Orlanducci F, Thibult ML, Pastor S, Fitzgibbon $\mathrm{J}$, et al. The co-receptor BTLA negatively regulates human Vgamma9Vdelta2 T-cell proliferation: a potential way of immune escape for lymphoma cells. Blood (2013) 122:922-31. doi: 10.1182/blood-2012-11-464685

30. Fisher JP, Heuijerjans J, Yan M, Gustafsson K, Anderson J. gammadelta $\mathrm{T}$ cells for cancer immunotherapy: a systematic review of clinical trials. Oncoimmunology (2014) 3:e27572. doi: 10.4161/onci.27572

31. Ribeiro ST, Ribot JC, Silva-Santos B. Five layers of receptor signaling in gammadelta T-cell differentiation and activation. Front Immunol. (2015) 6:15. doi: 10.3389/fimmu.2015.00015

32. Zumwalde NA, Sharma A, Xu X, Ma S, Schneider CL, Romero-Masters J C, et al. Adoptively transferred Vgamma9Vdelta2 $\mathrm{T}$ cells show potent antitumor effects in a preclinical B cell lymphomagenesis model. JCI Insight (2017) 2:93179. doi: 10.1172/jci.insight.93179
33. Iwasaki M, Tanaka Y, Kobayashi H, Murata-Hirai K, Miyabe H, Sugie $\mathrm{T}$, et al. Expression and function of PD-1 in human gammadelta $\mathrm{T}$ cells that recognize phosphoantigens. Eur J Immunol. (2011) 41:345-55. doi: 10.1002/eji.201040959

34. Kinter AL, Godbout EJ, McNally JP, Sereti I, Roby GA, O'Shea MA, et al. The common gamma-chain cytokines IL-2, IL-7, IL-15, and IL-21 induce the expression of programmed death-1 and its ligands. J Immunol. (2008) 181:6738-46. doi: 10.4049/jimmunol.181.10.6738

35. Austin JW, Lu P, Majumder P, Ahmed R, Boss JM. STAT3, STAT4, NFATc1, and CTCF regulate $\mathrm{PD}-1$ through multiple novel regulatory regions in murine T cells. J Immunol. (2014) 192:4876-86. doi: 10.4049/jimmunol.1302750

36. Lam LT, Wright G, Davis RE, Lenz G, Farinha P, Dang L, et al. Cooperative signaling through the signal transducer and activator of transcription 3 and nuclear factor-\{kappa\}B pathways in subtypes of diffuse large Bcell lymphoma. Blood (2008) 111:3701-13. doi: 10.1182/blood-2007-09-1 11948

37. Zhu F, Hwang B, Miyamoto S, Rui L. Nuclear import of JAK1 is mediated by a classical NLS and is required for survival of diffuse large B-cell lymphoma. Mol Cancer Res.(2017) 15:348-57. doi: 10.1158/1541-7786.MCR-16-0344

38. Ngo VN, Young RM, Schmitz R, Jhavar S, Xiao W, Lim KH, et al. Oncogenically active MYD88 mutations in human lymphoma. Nature (2011) 470:115-9. doi: 10.1038/nature09671

39. Rovira J, Karube K, Valera A, Colomer D, Enjuanes A, Colomo L, et al. MYD88 L265P mutations, but no other variants, identify a subpopulation of DLBCL patients of activated B-cell origin, extranodal involvement, and poor outcome. Clin Cancer Res. (2016) 22:2755-64. doi: 10.1158/1078-0432.CCR$15-1525$

40. Yang C, Ko B, Hensley CT, Jiang L, Wasti AT, Kim J, et al. Glutamine oxidation maintains the TCA cycle and cell survival during impaired mitochondrial pyruvate transport. Mol Cell (2014) 56:414-24. doi: 10.1016/j.molcel.2014.09.025

41. Qi W, Keenan HA, Li Q, Ishikado A, Kannt A, Sadowski T, et al. Pyruvate kinase M2 activation may protect against the progression of diabetic glomerular pathology and mitochondrial dysfunction. Nat Med. (2017) 23:753-62. doi: $10.1038 / \mathrm{nm} .4328$

42. Fernandez-de-Cossio-Diaz J, Vazquez A. Limits of aerobic metabolism in cancer cells. Sci Rep. (2017) 7:13488. doi: 10.1038/s41598-017-14071-y

43. Cacace A, Sboarina M, Vazeille T, Sonveaux P. Glutamine activates STAT3 to control cancer cell proliferation independently of glutamine metabolism. Oncogene (2017) 36:2074-84. doi: 10.1038/onc.2016.364

44. Jin L, Alesi GN, Kang S. Glutaminolysis as a target for cancer therapy. Oncogene (2016) 35:3619-25. doi: 10.1038/onc.2015.447

Conflict of Interest Statement: The authors declare that the research was conducted in the absence of any commercial or financial relationships that could be construed as a potential conflict of interest.

Copyright $\odot 2018$ Xia, Zhou, Guo, Fu, Zhu, Li, Xu, Zheng, Zhang, Shan and Gao. This is an open-access article distributed under the terms of the Creative Commons Attribution License (CC BY). The use, distribution or reproduction in other forums is permitted, provided the original author(s) and the copyright owner(s) are credited and that the original publication in this journal is cited, in accordance with accepted academic practice. No use, distribution or reproduction is permitted which does not comply with these terms. 